\title{
El nacionalismo musical: una mirada a partir de dos obras representativas para banda sinfónica de compositores latinoamericanos
}

Musical Nationalism: a Look from Two Representative Works for Symphonic Band by Latin American Composers

Juan Carlos Meza Solano

DOI 10.15517/es.v81i1.47283

(c) (i) (8) E Esta obra está bajo una licencia Creative Commons

By Na ND Reconocimiento-No comercial-Sin Obra Derivada 


\title{
El nacionalismo musical: una mirada a partir de dos obras representativas para banda sinfónica de compositores latinoamericanos
}

\author{
Musical Nationalism: a Look from Two Representative Works \\ for Symphonic Band by Latin American Composers
}

\author{
Juan Carlos Meza Solano ${ }^{1}$ \\ Universidad de Costa Rica \\ Cartago, Costa Rica
}

Recibido: 23 de julio del 2019 Aprobado: 20 de diciembre de 2019

\begin{abstract}
Resumen
El nacionalismo musical, concebido como la búsqueda de una identidad cultural propia a través de la utilización de elementos folclóricos, es una tendencia que ha tenido un impacto en la música compuesta para banda sinfónica durante los siglos XX y XXI. Las posibilidades que ofrece este movimiento a los compositores son muy ricas y variadas, ya que permiten nuevas formas de expresión con recursos muy particulares. Al mismo tiempo, esto ha hecho que instrumentistas y directores deban estudiar y aprender ciertos rasgos de la música de distintas regiones para acercarse lo más fielmente posible a lo que los compositores desean expresar. De esta manera, la práctica de utilizar elementos nacionalistas en obras latinoamericanas para banda sinfónica ha sido abordada en este trabajo desde la interpretación de dos obras representativas: Suite 200 (2010), del colombiano Victoriano Valencia (1970), y Preludio y Scherzo (2009), del costarricense Vinicio Meza (1968).
\end{abstract}

Palabras claves: música; nacionalismo; banda; cultura; latinoamérica.

1 Profesor Asociado en la Escuela de Artes Musicales, Universidad de Costa Rica. Trompetista Principal, Orquesta Sinfónica Nacional de Costa Rica, Centro Nacional de la Música, Ministerio de Cultura y Juventud. Máster en Música con Énfasis en Dirección de Bandas por la Universidad de Costa Rica. ORCID: 0000-0002-2447-0694. Correo electrónico: juan.meza@ucr.ac.cr 
El nacionalismo musical: una mirada a partir de dos obras representativas

Artículo para banda sinfónica de compositores latinoamericanos

\begin{abstract}
Nationalism in music, conceived as the search for the identity of a particular culture through the use of folkloric elements, is a trend that has had an impact on the music composed for symphonic band during the XX and XXI century. The possibilities that this movement offers to the composers are very rich and varied, allowing them new forms of expression with very particular resources. At the same time, this has made musicians and directors study and learn certain musical features from different regions, in order to get as close as possible to what the composers wished to express. Thus, the practice of using nationalistic elements in Latin American works for symphonic band has been approached in this study regarding the interpretation of two representative works: Suite 200 (2010), by Colombian composer Victoriano Valencia (1970); Preludio and Scherzo (2009) by Costa Rican Vinicio Meza (1968)
\end{abstract}

Key words: music; nationalism; band; culture; Latin America. 


\section{Introducción}

A través de la historia, la música (como disciplina de las artes) y el músico-artista han encontrado numerosos obstáculos tanto para ser reconocidos como para ser accesibles al público en general. La historia nos dice que los grandes compositores ocupaban un lugar inferior en la sociedad, pero esto no era así "para un escritor como Aretino o un artista de la talla de Miguel Ángel" (Robertson \& Stevens, 1985, p. 14). Sin embargo, hoy, la humanidad puede disfrutar de la música realizada por grandes compositores en varios periodos históricos. Esto gracias, en parte, a que se cuenta con herramientas tecnológicas que permiten que la información y, en este caso, la música estén disponibles de una manera fácil y rápida para la sociedad. Así, distintas regiones en el mundo se ven enriquecidas con aportes de otras latitudes, lo cual facilita la influencia de unas sobre otras.

Si bien la música, en general, no obedece estrictamente a los momentos históricos de la humanidad, sí hay tendencias sociales y políticas que han influenciado movimientos musicales. Uno de estos es el nacionalismo, al cual se han adscrito grandes obras musicales. En este artículo se abordará el movimiento nacionalista, a partir de rasgos generales universales y con énfasis en su desarrollo en Latinoamérica durante el siglo XX, específicamente, en dos obras para banda sinfónica. Asimismo, se hará referencia a los compositores que las crearon: Victoriano Valencia (Suite 200) y Vinicio Meza (Preludio y Scherzo).

El presente artículo no se enfoca en un análisis musical sistemático de cada obra, sino en un marco más general de los trabajos de Meza y Valencia. Al hacer uso de variados recursos técnicos y compositivos se abordarán elementos representativos del nacionalismo en la música para banda sinfónica. Estas obras no solamente tienen un valor plausible en la búsqueda de identidad de una región o país determinado, sino que también han significado un aporte importante para el denominado comúnmente como repertorio universal de banda.

\section{Nacionalismo-universalismo}

Es posible que la antítesis nacionalismo-universalismo haya sido y sea en la actualidad, el punto de partida para algunos compositores. De esta forma, se plantean la siguiente interrogante: ¿deben necesariamente incluir en su música rasgos folclóricos de su país o región con un lenguaje nacionalista o, por el contrario, deben más bien desproveerse de ellos apuntando hacia un lenguaje universal, que no admita la afiliación a una escuela o tendencia específica? Si se decantan por la primera opción se debe definir, además, qué camino se va a seguir dentro de ese movimiento; si usará el material autóctono de manera literal, abstracta o una combinación de ambas, es decir, cómo lo procesará. Kuss (1998) agrega que: 
Por otro lado, este arsenal flolklórico/popular es vastísimo. Debemos entonces preguntarnos, ¿qué elementos selecciona el compositor de este vasto repertorio? ¿A través de qué mecanismos se opera esta selección? ¿Cuál es la actitud del compositor con respecto a la "autenticidad" del folklore con el cual se identifica? ¿LO recoge, transcribe, y clasifica minuciosamente, como lo hizo Bartök, adquiriéndolo como "una lengua materna" (sus propias palabras) y al copiarlo lo absorbía, como hizo Bach con los conciertos de Vivaldi? ¿Lo asimila asistemática e intuitivamente, "por los poros", sin intentar analizarlo científicamente, como lo hizo Villalobos, en sus viajes al interior de Brasil? ¿Lo absorbe en sus formas urbanas, ya "corruptas" (lo que el gran musicólogo cubano Argeliers León llamó "el factor urbano elaborado"), como lo hicieron Stravinsky o Ginastera, tomándolo de antologías "armonizadas"? O simplemente lo inventa, como lo hizo el argentino Pascual de Rogatis (p. 139).

También pueden entrar en juego otras consideraciones. Por ejemplo, la separación o el acercamiento entre música culta o académica y popular; un tema que ha causado mucha controversia y que da para pensar que quizá alguien con una tendencia universalista debería evitar o, por qué no, pensar más bien en una conciliación de ambas, pudiendo utilizarlas indistintamente sin que exista una contradicción entre ellas. Según Béhague (2006) hay cuestionamientos que pueden surgir a raíz de esta antítesis

Es importante recordar que las figuras más internacionalmente conocidas del nacionalismo musical latinoamericano no han sido exclusivamente nacionalistas, sea un Carlos Chávez, un Villa-Lobos o un Alberto Ginastera. Chávez, como Villa-Lobos, llegó a creer que el arte debe ser nacional en su carácter, pero universal en su fundamento y debe llegar a todo el pueblo (p. 50).

\section{El nacionalismo en Latinoamérica}

En América Latina, el triunfo del nacionalismo político de finales del siglo XIX influyó en el desarrollo de la música y las artes, por lo que no fueron ajenas a esta fuerza ideológica orientada hacia la búsqueda de una identidad cultural propia. Hubo un intento de unión entre las técnicas europeas y los elementos melódicos y rítmicos propios del folclore de los países latinoamericanos. Algunos compositores representativos de esta época son: José María Valle Riestra (1858-1925) y Pascual de Rogatis (1880-1980). Posteriormente, en el siglo XX, aparecen varios compositores importantes, por ejemplo, el brasileño Heitor Villa-Lobos (1887-1959); los mexicanos Carlos Chávez (1899-1978), Silvestre Revueltas (1899-1940) y 
Julián Carrillo (1875-1965), y el argentino Alberto Ginastera (1916-1983), quien es uno de los precursores de la tendencia orientada hacia la utilización de temas populares con un papel muy importante, claro está. Sin embargo, estas tendencias ya no se presentan con la claridad del nacionalismo de finales del siglo XIX. En palabras de Sánchez (2011):

Esta tendencia estética supone la realización de una música en la que los motivos de corte popular están presentes en la base de la creación, pero no cristalizan en obras donde sobresalgan las citadas melodías populares, sino que se convierten en melodías inventadas desde sus giros característicos pero sometidas a la imaginación del compositor, en un profundo proceso de elaboración y transformación previo a su presentación final, una sublimación del folclore (pp. 10-11).

Asimismo, Chase (1947) agrega que "la cultura musical en América Latina descansa en gran medida sobre el fundamento de la tradición popular; o, más precisamente, sobre una estrecha correlación entre la tradición popular de la música folklórica y la tradición académica del arte musical” (p.15).

Varios autores han aportado en relación con el nacionalismo musical en Latinoamérica; algunos se han enfocado en la música y analizado si esta contiene elementos para ser considerada dentro del movimiento nacionalista. Otros autores, más bien, se han concentrado en los compositores y cómo su formación e influencias de otros contextos les permiten, o no, ser considerados como creadores de composiciones con rasgos nacionalistas. En el 2009, Tinoco desarrolló la investigación llamada El nacionalismo en la obra para piano solo del compositor brasileño Camargo Guarnieri. En esta se analiza el estilo del compositor y se verifica si su compromiso con la estética nacionalista modernista se plasma en su obra musical, en el marco de la musicología histórica.

En 2010, Parra desarrolló una investigación documental sobre la obra de la compositora Modesta Bor. Se analizaron los estilos de composición que se evidencian en su producción y se organizaron desde el punto de vista nacionalista. Es un aporte significativo al conocimiento de la música académica y folclórica latinoamericana y contribuye a difundir, documentar y valorar los compositores venezolanos.

Por otra parte, Picún y Carredano (2012) en su artículo "El nacionalismo musical mexicano: una lectura desde los sonidos y los silencios", después del análisis realizado, coinciden en un nuevo enfoque en el que se plantea que el nacionalismo musical no es del todo homogéneo. Al respecto, plantean dos posiciones: 
Por un lado, están los discursos centrados en cuestiones musicales, que apuntan a la construcción de una música nacionalista, basada en la apropiación selectiva de las clases subalternas, así como en la música anterior a la conquista. Por otro, los discursos centrados en la función social de la música, en particular, como medio de la lucha de clases (Picún y Carredano, 2012, p. 23).

En 1953, Falabella realizó un ensayo en el que plasmó mucho de lo realizado en la construcción de una historia musical en Latinoamérica. Esto por medio de la influencia de los compositores europeos y las luchas de estas tendencias con el folclor de la región, refiere cómo, en un inicio, se dio la influencia de la música europea nacionalista y la manera en que, posteriormente, los compositores latinoamericanos lo abordaron desde los propios elementos histórico-musicales de sus diferentes países, como en el caso de Brasil, México, Chile y Venezuela, entre otros.

Otros autores, como Miranda y Tello (2011) en La música en Latinoamérica; Tello (2004) en Aires nacionales en la música de América Latina como respuesta a la búsqueda de identidad; Cruz (2002) en Folclore, Música y Nación: el papel del bambuco en la construcción de lo colombiano; Béhague (1983), Plesch (2008) y Vilar (2004) hacen referencia, en general, al nacionalismo musical desde una perspectiva historiográfica, con la cual rescatan mayormente el valor del compositor latinoamericano y nacional en cada caso específico. Además, de manera particular, apuntan cómo estos compositores han sabido rescatar los elementos folclóricos en su producción musical.

Como se puede ver, el nacionalismo musical latinoamericano se ha investigado desde hace ya muchas décadas. Su desarrollo continuó en el siglo XX y aún hoy, en pleno siglo $X X I$, se encuentran compositores que podrían estar adscritos a esta tendencia. Las evidencias empíricas que se encuentran básicamente enfatizan o hacen referencia a la historia musical, pero no a las implicaciones que tienen las obras musicales consideradas como nacionalistas para las agrupaciones que las ejecutan, como es el caso, por ejemplo, de las bandas sinfónicas.

El fenómeno se dio tanto en Europa como en los Estados Unidos y en América Latina con un matiz especial, ya que algunos compositores de la primera mitad del siglo XX combinaron un marcado nacionalismo con rasgos vanguardistas. En Costa Rica también repercutió la tendencia musical nacionalista, aunque según Chatski (2012) "con mayor presencia en las artes plásticas, la literatura y la arquitectura" (p. 2). Sin embargo, sí se puede hablar de la existencia de obras musicales que entran dentro del movimiento nacionalista, ya que varios 
compositores, entre quienes destacan Julio Mata, Alcides Prado, Julio Fonseca y Alejandro Monestel, utilizaron ritmos y líneas melódicas que fueron recopiladas en jornadas de búsqueda en Guanacaste. Chatski (2012) apunta que en 1927 Luis Dobles Segreda, entonces secretario de Educación Pública, reunió a compositores, intérpretes y maestros de música con la finalidad de discutir sobre el estado de la música nacional en Costa Rica. Como resultado de esa cita se organizaron jornadas de expedición en busca de "lo nacional" en la música, las cuales se realizaron, posteriormente, en la región de Guanacaste.

Además, Chatski (2012) destaca que hubo dos tendencias nacionalistas: la primera de ellas está relacionada con la manera en cómo el compositor usa el material musical ajeno, precisamente las melodías folclóricas y populares recopiladas en las expediciones, y lo transforma para ser expuesto en obras de grandes formatos como fantasías y rapsodias. La segunda tendencia está ligada a utilizar motivos literarios nacionalistas, sin estar necesariamente vinculados al lenguaje musical.

Entonces, se entiende que en Latinoamérica el proceso de desarrollo musical no fue el mismo que en Europa, ni obedeció a los mismos valores y elementos culturales. Se trata de "un arte regido por un constante rejuego de confrontaciones entre lo propio y lo ajeno, lo autóctono y lo importado" (Carpentier, 2004, p. 7). Muchos compositores latinoamericanos de principios del siglo XX se encasillaron en la "onda folclórica", a veces pura, otras veces no tanto. Utilizaban la esencia del folclore y la combinaban con técnicas más avanzadas, tomadas, por lo general, de modelos europeos. Aquí radica la importancia de esta tendencia, porque no consiste simplemente en tomar un tema -llámese folclórico o popular- y valerse de ello para dar un carácter peculiar o nacional a una obra. Más bien se trata del abordaje que se le dé a ese tema con distintos y variados recursos. Se trata de una absorción de la esencia de un folclore musical que podrá ser trabajado posteriormente, de muy diversas formas, y que dio lugar a la aparición de una escuela de composición que caracterizó una etapa importante de la evolución de la música, orientada hacia la búsqueda de nuevas estéticas propias (regionales) diferenciadas de las universales, sobre todo de las occidentales. Es decir, la necesidad de la autoidentificación y realización en sus propias obras.

Así las cosas, algunos compositores de música de concierto lograron plasmar en sus obras la asimilación o recreación de la música popular vernácula, ya sea de manera directa o indirecta, evidente o difuminada, explícita o no. Es decir, un compositor puede, o no, conservar todos los elementos de la canción popular folclórica, pero, por otro lado, puede variar algunos de estos: la melodía, la armonía, la forma, el ritmo, entre otros. Asimismo, Cordero (2004) agrega que: 
Junto a creaciones intensamente nacionalistas de carácter local -ya sea con la cita folklórica o popular directa, ya sea con un folklorismo vestido de etiqueta- encontramos a compositores vinculados estrechamente a los movimientos internacionales de vanguardia (p. 154).

Muchos de esos elementos pueden trabajarse, en efecto, con recursos europeos, como el lenguaje armónico y los timbres instrumentales provenientes de ese continente, por mencionar algunos. Sin embargo, aquí entra la capacidad, habilidad, creatividad y originalidad del compositor. Para tal efecto, la investigación y la experimentación juegan un papel muy importante, así como un buen conocimiento, tanto de lo propio como de lo externo. Estos aspectos son, entre otros, los que hicieron avanzar la llamada música de concierto en América Latina, lo cual contribuyó en buena medida a la formación de una nueva conciencia estética y aportando a la música universal.

En este ámbito del nacionalismo musical moderno latinoamericano y dentro de la llamada música culta, varios países se distinguen por la representatividad de su creación musical. Por ejemplo, Brasil, con Heitor Villa-Lobos (1887-1959); México, con Silvestre Revueltas (1899-1940), y Cuba, con Amadeo Roldán (1900-1939), entre otros. Estos tres compositores fueron evidentemente nacionalistas, pero en su momento fueron además vanguardistas, al utilizar nuevos elementos que no habían sido usados antes. Hallaron una personalidad propia a través de sus músicas nacionales y como Villa-Lobos mismo dijo: "cuando un artista encuentra su acento verdadero, siempre es original y avanzado, aunque no tenga conciencia de ello" (citado en Carpentier, 2004, p. 58). En palabras de Béhague (2006):

Esta fue una actitud en realidad totalmente nueva que puede ser interpretada de varias maneras, pero que básicamente afirmaba la esencia de una conciencia estética única (oriunda de su propia cultura) y tal vez la intuición de que, frente a la dominación europea tradicional, el compositor latinoamericano si podía ofrecer algo diferente e igualmente válido (p. 48).

En la actualidad, varios compositores de nuevas generaciones están desarrollando, a veces con tendencias nacionalistas, un gran aporte al repertorio de banda sinfónica de América Latina, en el que se puede ver claramente la incorporación de elementos de composición que sugieren una tendencia hacia la música nacionalista. Dos de estos importantes compositores son Victoriano Valencia (1970), en Colombia, y Vinicio Meza (1968), en Costa Rica. Para entender el contexto de las bandas sinfónicas en Latinoamérica se requiere una 
breve explicación de sus orígenes en la historia y, en alguna medida, una justificación del porqué se eligió para este artículo este grupo instrumental sobre otros, especialmente sobre la orquesta sinfónica.

La familia de los instrumentos de viento y percusión ofrece una gran gama de colores, timbres y dinámicas en comparación con la orquesta. La diferencia básica con la orquesta sinfónica es la sección de cuerdas, lo cual tampoco debe entenderse como una limitación. Esto se compensa con otros recursos que usualmente no están disponibles en la orquesta. Por un lado, la orquesta generalmente no usa secciones completas de flautas (flauta 1, 2, 3; pícolo; flauta alto), clarinetes (clarinete Eb; clarinetes Bb 1, 2 y 3; clarinete Alto Eb; clarinete bajo Bb; clarinete contrabajo Eb) y trompetas (trompetas 1, 2 y 3; cornetas 1 y 2; fliscornos 1 y 2). Además, la familia de los saxofones y el eufonio rara vez se usan. En la banda, por el contrario, esta ampliación de las secciones permite posibilidades armónicas que usualmente no son posibles en la instrumentación orquestal genérica. Este recurso, entre otros, proporciona potencia y soporte armónico dentro de una misma sección.

Por otro lado, en términos generales es más fácil cargar o transportar la mayoría de los instrumentos de viento y percusión, lo cual representa otro recurso favorable, pues los músicos tienen la posibilidad de poder marchar, tocar sentados o de pie, en teatros o lugares cerrados, pero también al aire libre (siempre que el clima no dañe los instrumentos). Además, por lo general su precio es más bajo que el de los instrumentos de cuerda. Estas singularidades provocan que las bandas y los instrumentos de vientos y percusión sean más flexibles en su funcionalidad. Por esto, en sus orígenes se usaron principalmente en la música militar, para salones, la iglesia, la pista de baile; es decir, de forma utilitaria.

De acuerdo con Caines (2012), es difícil encontrar obras que no tengan una intención utilitaria o que no entren en la categoría de transcripciones de cuerdas u obras orquestales. Menciona excepciones de algunas canzonas para bronces (instrumentos de metal) realizadas por compositores como Gabrielli, Teilman Susato, Jean Baptiste Lully, y algunas partes de la música de los Reales Fuegos Artificiales de Handel. Agrega, además, que la gran mayoría de las obras escritas para vientos antes del siglo XIX eran marchas, música para salones de baile, fanfarrias y música funcional para eventos. Esta realidad fue plausible también en América Latina. Valencia (2017) ilustra el caso colombiano, que es similar en distintos países latinoamericanos, de la siguiente manera: 
El rol militar de las agrupaciones de vientos y percusión es característico en las bandas colombianas hasta el periodo de la Independencia (Valencia, 2014). A partir de 1820 se genera la transformación de aquella funcionalidad en nuevos roles, como el de servicio religioso y oficial. Los géneros básicos son marchas, himnos y música sacra, y posteriormente vals, minuet y contradanza, generándose un repertorio criollo creado a partir de las características de estos géneros de tradición europea. Sin autores conocidos de la mayor parte de esta producción, el sentido básico de la creación estaba en satisfacer las demandas institucionales de los oficios ya descritos, el militar, el religioso y el oficial, y, en forma posterior y progresiva, en satisfacer las necesidades de entretenimiento y disfrute de la población. El arreglista-compositor es un individuo al servicio de las necesidades del formato en su interacción con las demandas del contexto (p. 104).

Cuando hacemos un breve repaso de las obras escritas para vientos por compositores como Bach, Mozart o Beethoven, se puede comprobar que la producción en ese campo es mínima, en comparación con la cantidad de obras para piano, cuerdas o canto. Incluso, compositores universales románticos tampoco fueron muy prolíficos en su obra para vientos.

A finales del siglo XIX e inicios y mediados del siglo $X X$, surgieron figuras muy importantes para el mundo de las bandas. John Philip Sousa (1854-1932), Frederick Fennell (1914-2004), Percy Grainger (1882-1961), Ralph Vaughan Williams (1872-1958), Robert Austin Boudreau (1927), William D. Revelli (1902-1994), entre otros hicieron un esfuerzo para hacer trascender la música de bandas. Ellos iniciaron toda una transformación orientada hacia la estandarización y legitimación de la música de bandas como algo que pudiera ser homologado a cualquier otro género o agrupación sinfónica, con el mismo estándar artístico. Esto implicó el fomento y la creación no solo de nuevos formatos instrumentales a partir de los instrumentos de viento y percusión, sino de un repertorio completamente nuevo y diferente, alejado de la música para efectos utilitarios y llevado ahora a las salas de concierto, a públicos que estaban acostumbrados a la música orquestal.

En todo este proceso fue muy importante la creación, en 1952, del Eastman Wind Ensemble, por Frederick Fennell. De acuerdo con Caines (2012), el cambio radical en la instrumentación, tal como lo redefinió Fennell en 1952, fue el principal catalizador en el interés de la escritura y ejecución de obras para grupos instrumentales de viento. Es así como durante los siglos XX y XXI, una gran cantidad de compositores han hecho un importante aporte a la literatura universal de música para vientos y percusión, independientemente del 
formato. Caines (2012) presenta los siguientes cuadros, en los que define las características de distintos formatos de grupos instrumentales dentro de la familia de los instrumentos de vientos y percusión. En general, las diferencias son muy pequeñas, pero importantes.

Cuadro 1. Instrumentación según formato de ensamble.

\begin{tabular}{|c|c|c|}
\hline Ensemble [Ensamble] & $\begin{array}{l}\text { Instrumentation } \\
\text { [Instrumentación] }\end{array}$ & $\begin{array}{l}\text { Additions and Variations } \\
\text { [Adiciones y variaciones] }\end{array}$ \\
\hline $\begin{array}{l}\text { Symphonic Band/Concert Band } \\
\text { The instrumentation of the Symphonic } \\
\text { Band is very similar to the Wind } \\
\text { Ensemble. The crucial difference is that } \\
\text { there are multiple people playing each } \\
\text { part. The model of the Symphonic band } \\
\text { is that of the military band. } \\
\text { Banda sinfónica/Banda de concierto } \\
\text { [La instrumentación de la banda } \\
\text { sinfónica es muy similar al ensamble } \\
\text { de vientos. La diferencia crucial es } \\
\text { que hay muchas personas tocando } \\
\text { cada parte. El modelo de la banda } \\
\text { sinfónica es aquel de la banda militar]. }\end{array}$ & 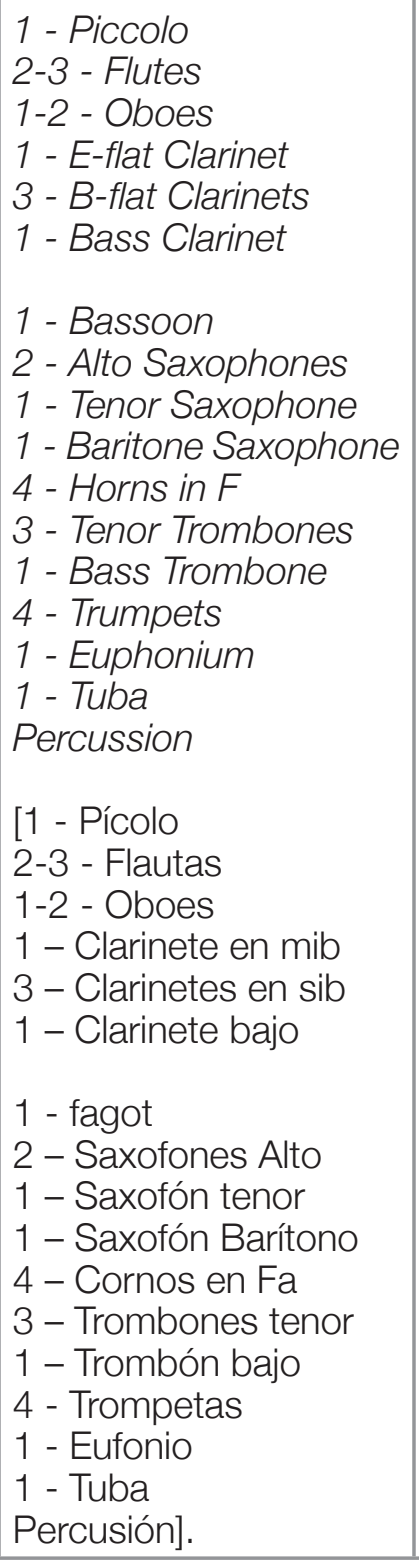 & $\begin{array}{l}\text { English Horn is less common } \\
\text { in standard Symphonic Band } \\
\text { instrumentation. } \\
\text { String Bass is a common } \\
\text { additionto the Symphonic } \\
\text { Band, but is not part of } \\
\text { the standard instrumentation. } \\
\text { Piano and Harp are rarely } \\
\text { part of the instrumentation, } \\
\text { but they will be included } \\
\text { when required. } \\
\text { [El corno inglés es menos } \\
\text { común en la instrumentación } \\
\text { estándar de banda sinfónica. } \\
\text { El contrabajo es una adición } \\
\text { común a la banda sinfónica, } \\
\text { pero no es parte de la } \\
\text { instrumentación estándar. } \\
\text { Piano y arpa raramente son } \\
\text { parte de la instrumentación, } \\
\text { pero serán incluidos cuando } \\
\text { sean requeridos]. }\end{array}$ \\
\hline
\end{tabular}


El nacionalismo musical: una mirada a partir de dos obras representativas

Artículo para banda sinfónica de compositores latinoamericanos

\begin{tabular}{|c|c|c|}
\hline Ensemble [Ensamble] & $\begin{array}{l}\text { Instrumentation } \\
\text { [Instrumentación] }\end{array}$ & $\begin{array}{l}\text { Additions and Variations } \\
\text { [Adiciones y variaciones] }\end{array}$ \\
\hline $\begin{array}{l}\text { The Sousa Band } \\
\text { The Sousa Band has a few very } \\
\text { specific features to it, though } \\
\text { essentially it was a Concert Band. } \\
\text { [La banda Sousa] } \\
\text { [La banda Sousa tiene algunas } \\
\text { características muy específicas, } \\
\text { aunque esencialmente era una } \\
\text { banda de concierto]. }\end{array}$ & $\begin{array}{l}3 \text { - Flutes (one } \\
\text { doubling on Piccolo) } \\
2 \text { - Oboes (one } \\
\text { doubling on } \\
\text { English Horn) } \\
1 \text { - Bassoon } \\
9 \text { - B-flat Clarinets (1-2 } \\
\text { doubling on E-flat } \\
\text { Clarinet) } \\
1 \text { - Bass Clarinet } \\
4 \text { - Saxophones } \\
4 \text { - Horns in F } \\
6 \text { - Cornets } \\
2 \text { - Trumpets } \\
3 \text { - Trombones } \\
2 \text { - Euphoniums } \\
3 \text { - Tubas } \\
\text { (Sousaphones) } \\
3 \text { - Percussionists } \\
\text { [3 - Flautas (una } \\
\text { doblando el pícolo) } \\
2 \text { - Oboes (uno } \\
\text { doblando el corno } \\
\text { inglés) } \\
1 \text { - Fagot } \\
9 \text { - Clarinetes en Sib } \\
\text { (1-2 doblando el } \\
\text { clarinet en mib) } \\
1 \text { - Clarinete bajo } \\
4 \text { - Saxofones } \\
4 \text { - Cornos en Fa } \\
6 \text { - Cornetas } \\
2 \text { - Trompetas } \\
3 \text { - Trombones } \\
2 \text { - Eufonios } \\
3 \text { - Tubas (Sousáfonos) } \\
3 \text { - Percusionistas] }\end{array}$ & $\begin{array}{l}\text { The main differences are in } \\
\text { the number of clarinets and } \\
\text { tubas. The Sousa band also } \\
\text { always toured with a soprano } \\
\text { soloist. This made and } \\
\text { ensemble of } 44 \\
\text { including the soprano. } \\
\text { Sousa did not include string } \\
\text { bass, but would occasionally } \\
\text { include a pianist or harpist } \\
\text { when needed. } \\
\text { [Las principales diferencias } \\
\text { están en el número de } \\
\text { clarinetes y tubas. } \\
\text { La banda de sousa siempre } \\
\text { estuvo de gira con un } \\
\text { soprano solista. Esto hizo un } \\
\text { ensamble de } 44 \text { incluyendo } \\
\text { el soprano } \\
\text { No incluyó contrabajo, pero } \\
\text { ocasionalmente incluiría un } \\
\text { pianista o arpista cuando } \\
\text { fuera necesario]. }\end{array}$ \\
\hline
\end{tabular}




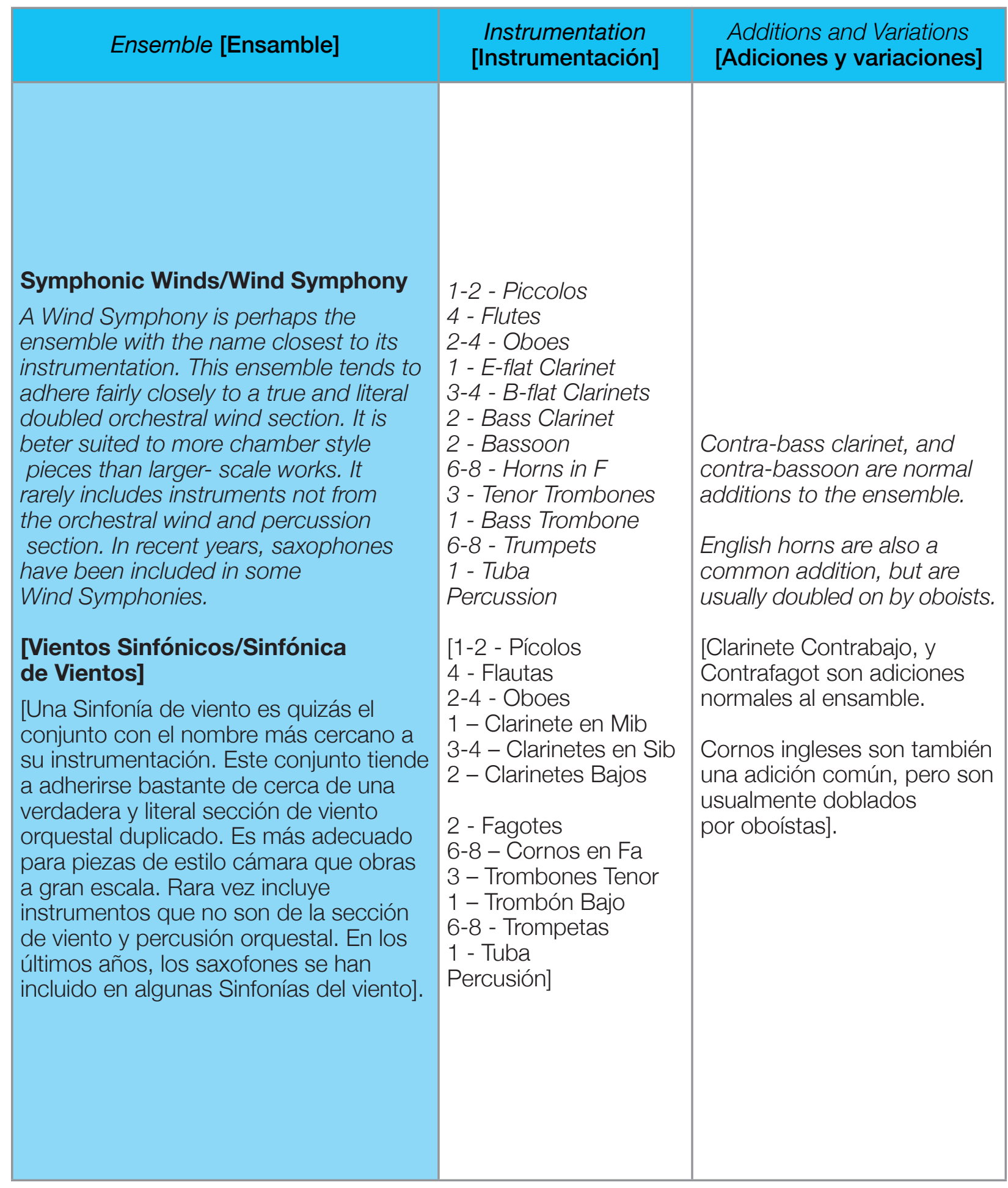


nacionalismo musical: una mirada a partir de dos obras representativas

Artículo para banda sinfónica de compositores latinoamericanos

\begin{tabular}{|c|c|c|}
\hline Ensemble [Ensamble] & $\begin{array}{l}\text { Instrumentation } \\
\text { [Instrumentación] }\end{array}$ & $\begin{array}{l}\text { Additions and Variations } \\
\text { [Adiciones y variaciones] }\end{array}$ \\
\hline $\begin{array}{l}\text { Wind Ensemble } \\
\text { The Wind Ensemble is a one-to- a-part } \\
\text { ensemble that features variable and } \\
\text { flexible instrumentation. This allows } \\
\text { composers the freedom to write for } \\
\text { any instrumentation they desire. } \\
\text { [Ensamble de Vientos] } \\
\text { [El ensamble de vientos es un ensamble } \\
\text { de uno por parte que se caracteriza por } \\
\text { una instrumentación variable y flexible. } \\
\text { Esto permite a los compositores la } \\
\text { libertad de escribir para cualquier } \\
\text { instrumentación que deseen]. }\end{array}$ & $\begin{array}{l}1 \text { - Piccolo } \\
\text { 2-3 - Flutes } \\
1 \text {-2 - Oboes } \\
1 \text { - English Horn } \\
1 \text { - E-flat Clarinet } \\
3 \text { - B-flat Clarinets } \\
1 \text { - Bass Clarinet } \\
1 \text { - Bassoon } \\
2 \text { - Alto Saxophones } \\
1 \text { - Tenor Saxophone } \\
1 \text { - Baritone Saxophone } \\
4 \text { - Horns in F } \\
\text { 3 - Tenor Trombones } \\
1 \text { - Bass Trombone } \\
4 \text { - Trumpets } \\
1 \text { - Euphonium } \\
1 \text { - Tuba } \\
1 \text { - String Bass } \\
\text { Percussion } \\
\text { 1 - Pícolo } \\
2 \text {-3 - Flautas } \\
1 \text {-2 - Oboes } \\
1 \text { - Corno inglés } \\
1 \text { - Clarinete en Mib } \\
3 \text { - Clarinetes en Sib } \\
1 \text { - Clarinete Bajo } \\
1 \text { - Fagot } \\
2 \text { - Saxofón Alto } \\
1 \text { - Saxofón Tenor } \\
1 \text { - Saxofón Barítono } \\
4 \text { - Cornos en Fa } \\
3 \text { - Trombones Tenor } \\
1 \text { - Trombón Bajo } \\
4 \text { - Trompetas } \\
1 \text { - Eufonio } \\
1 \text { - Tuba } \\
1 \text { - Contrabajo } \\
\text { Percusión] }\end{array}$ & $\begin{array}{l}\text { There are normally } \\
\text { saxophones in } \\
\text { this ensemble. } \\
\text { String bass and } \\
\text { euphonium are } \\
\text { common additions. } \\
\text { [Normalmente hay } \\
\text { saxofones en } \\
\text { este ensamble. } \\
\text { El contrabajo y } \\
\text { el eufonio son } \\
\text { adiciones comunes.] }\end{array}$ \\
\hline
\end{tabular}




\begin{tabular}{|c|c|c|}
\hline Ensemble [Ensamble] & $\begin{array}{l}\text { Instrumentation } \\
\text { [Instrumentación] }\end{array}$ & $\begin{array}{l}\text { Additions and Variations } \\
\text { [Adiciones y variaciones] }\end{array}$ \\
\hline $\begin{array}{l}\text { Wind Orchestra } \\
\text { The extreme range in instrumentation } \\
\text { lies in the flexibility of the ensemble. } \\
\text { The concept of a Wind Orchestra is to } \\
\text { double a traditional wind section from } \\
\text { a symphony orchestra. However, as the } \\
\text { terms and standards for a wind orchestra } \\
\text { are even less defined than other } \\
\text { ensemble types, there is more room } \\
\text { for variation within this instrumentation } \\
\text { [Orquesta de Vientos] } \\
\text { [El rango extremo en la instrumentación } \\
\text { radica en la flexibilidad del conjunto. } \\
\text { El concepto de una orquesta de viento } \\
\text { es duplicar una sección de viento } \\
\text { tradicional de una orquesta sinfónica. } \\
\text { Sin embargo, como los términos } \\
\text { y estándares para una orquesta de } \\
\text { viento están aún menos definidos } \\
\text { que otros tipos de conjuntos, hay } \\
\text { más espacio para la variación dentro } \\
\text { de esta instrumentación]. }\end{array}$ & $\begin{array}{l}2 \text { - Piccolos } \\
\text { 4-6 - Flutes } \\
\text { 2-4 - Oboes } \\
\text { 1-2 - E-flat Clarinets } \\
6 \text { - B-flat Clarinets } \\
\text { 2 - Bass Clarinets } \\
\text { 1-2 - Contra-Bass } \\
\text { Clarinets } \\
\text { 2-4 - Bassoons } \\
\text { 1-2 - Contra Bassoons } \\
\text { 4-8 - Trumpets } \\
\text { 4-8 - Horns in F } \\
\text { 3-5 - Tenor Trombones } \\
\text { 1-2 - Bass Trombones } \\
\text { 1-2 - Tubas } \\
\text { Percussion } \\
\text { [2 - Pícolos } \\
4-6 \text { - Flautas } \\
\text { 2-4 - Oboes } \\
\text { 1-2 - Clarinetes en Mib } \\
6 \text { - Clarinetes en Sib } \\
\text { 2 - Clarinetes Bajos } \\
\text { 1-2 - Clarinetes } \\
\text { Contrabajos } \\
\text { 2-4 - Fagotes } \\
\text { 1-2 - Contrafagotes } \\
\text { 4-8 - Trompetas } \\
\text { 4-8 - Cornos en Fa } \\
\text { 3-5 - Trombones Tenor } \\
\text { 1-2 - Trombones Bajos } \\
\text { 1-2 - Tubas } \\
\text { Percusión] }\end{array}$ & $\begin{array}{l}\text { One may double on } \\
\text { English Horn. } \\
\text { Saxophones, Euphonium } \\
\text { and String Bass are } \\
\text { rarely included. } \\
\text { Addition of specialty } \\
\text { instruments like } \\
\text { saxophone are generally } \\
\text { only included as solo } \\
\text { instruments. The standard } \\
\text { instrumentation does not } \\
\text { include them. } \\
\text { Piano and harp are common } \\
\text { additions to the ensemble. } \\
\text { [Se puede doblar el } \\
\text { corno inglés. } \\
\text { Rara vez se incluyen } \\
\text { saxofones, eufonios } \\
\text { y contrabajos. } \\
\text { La adición de instrumentos } \\
\text { especiales como el saxofón } \\
\text { generalmente solo se incluye } \\
\text { como instrumento solista. } \\
\text { La instrumentación estándar } \\
\text { no los incluye. } \\
\text { El piano y el arpa son } \\
\text { adiciones comunes al } \\
\text { ensamble]. }\end{array}$ \\
\hline
\end{tabular}

Fuente: Caines, 2012, pp. 6-8. 
Aunque este proceso fue desarrollado principalmente en los Estados Unidos, con una influencia directa en su música y sociedad, tuvo sus implicaciones en Europa y Latinoamérica, donde podemos encontrar bandas incluso desde finales del siglo XVIII. Un ejemplo que ilustra este hecho es el caso colombiano. Valencia (2011) apunta que "en Colombia las primeras bandas militares se conformaron a finales del siglo XVIII, teniendo como primera referencia la Banda de la Corona con Pedro Carricarte en 1784, y muy pronto se proyectaron a los escenarios religiosos y posteriormente a los festivos" (p. 2). Otro claro ejemplo es Costa Rica, donde, ya antes de 1845, existían bandas en algunas provincias de este país. Sin embargo, su institucionalización se dio justamente en ese año, cuando mediante el Decreto No. 63 fue creado el Programa Nacional de Bandas (Meza, 2008).

\section{Suite 200 de Victoriano Valencia}

Victoriano Valencia² es un compositor y pedagogo musical centrado en la producción creativa desde la composición y los arreglos para banda, coro, orquesta sinfónica, orquesta popular y otros formatos, la producción discográfica y el diseño de materiales pedagógicos. Es Licenciado en Música por la Universidad Pedagógica Nacional (1995) y Magister en Composición por la Universidad EAFIT de Medellín (2012) (Valencia, s.f.a).

"Durante las dos últimas décadas, Valencia ha sido un motor fundamental en el crecimiento y la cualificación de la práctica bandística nacional colombiana y un referente creativo para las nuevas generaciones de músicos" (Valencia, s.f., párr. 1). Ha compuesto más de 150 obras para banda, entre arreglos y composiciones originales. Aborda lenguajes populares, sinfónicos y contemporáneos y es considerado uno de los compositores latinoamericanos más reconocidos en el mundo de las bandas sinfónicas. Poco a poco, ha logrado obtener reconocimiento internacional con sus obras, en las cuales logra amalgamar características autóctonas y técnica europea, con rasgos a veces románticos, otras veces modernistas, otras neoclásicos y, por supuesto, nacionales. Basta leer los prólogos o notas de muchas de sus obras para comprobar ese particular gusto por lo nacional colombiano o caribeño, en general. Sus obras han sido publicadas en Colombia (Scoremusical), así como en Europa, particularmente en España (Editorial Piles) y en Estados Unidos (Ludwig Masters). Sus composiciones están siendo ejecutadas en los continentes americano, europeo y asiático (Valencia, s.f.a).

${ }^{2}$ La información referente a Victoriano Valencia y su Suite 200 ha sido tomada en gran parte de su página web: www.victorianovalencia.com 
Muchas de sus obras demuestran que la técnica es solo un medio para expresar el pensamiento musical. Es decir, el hecho de que en la primera mitad del siglo XX muchos compositores latinoamericanos utilizaran recursos técnicos europeos no significó que no pudieran hacer una música latinoamericana pura. Se trata de elementos distintos, pero conciliables. Lo que importa es la manera con la que el artista puede imprimirle su sello personal o la identidad nacional a su obra; la actitud que asuma en cuanto a cómo debe o puede manejar los materiales con que trabaja y la técnica con que debe elaborarlos en el empeño de hacer un arte "americano-universal" (Carpentier citado por Müller-Bergh, 1969, p. 327), como lo llamaba Alejo Carpentier.

La música del maestro Victoriano evidencia, de diversas maneras, rasgos colombianos y afrocaribeños con gran originalidad. Un ejemplo claro es su Suite 200. De acuerdo con Valencia (2010) la obra fue comisionada por el Ministerio de Cultura de Colombia en el marco de la conmemoración del Bicentenario de la Independencia Nacional 1810-2010. "Está estructurada en cuatro movimientos y tiene una duración total aproximada de 28 minutos" (Valencia, s.f.b, párr. 1). Sobre el primer movimiento,

INTERDEPENDENCIA realiza un recorrido a través de diversas escenas del período independentista: Nueva Granada, El Florero y Cartagena, Patria Boba, Bolívar y República, alternando distintas facetas de dos temas principales que representan la imagen colonial (el otro) y el espíritu nacional, e intentando expresar la condición de inter-dependencia e inter-existencia en la configuración permanente de quiénes somos como nación e individuos (Valencia, s.f.b, párr. 1).

A manera de ilustración, aunque este escrito no pretende realizar un exhaustivo análisis de la obra, se aportarán algunas descripciones y ejemplos musicales, sobre todo de este primer movimiento, para que el lector pueda tener una idea más clara de la composición y el uso de elementos nacionalistas. Este primer movimiento inicia con una introducción muy enérgica (imagen 1), con elementos rítmicos colombianos (uso de la síncopa e instrumentos de percusión latina como las congas y la tambora al final) dispuestos en patrones de 3, 4, 5 y 6 pulsos.

Seguido de la "Introducción" aparece "Nueva Granada", que corresponde al primer período de la historia de la independencia de Colombia. El compositor intenta retratar este contexto a través de una atmósfera de "caos", que se puede encontrar ya desde los dos primeros compases, donde presenta pasajes de música aleatoria especialmente en los bronces 
El nacionalismo musical: una mirada a partir de dos obras representativas

Artículo para banda sinfónica de compositores latinoamericanos

Imagen 1. Suite 200, Victoriano Valencia. I movimiento: Interdependencia, compases 9-21
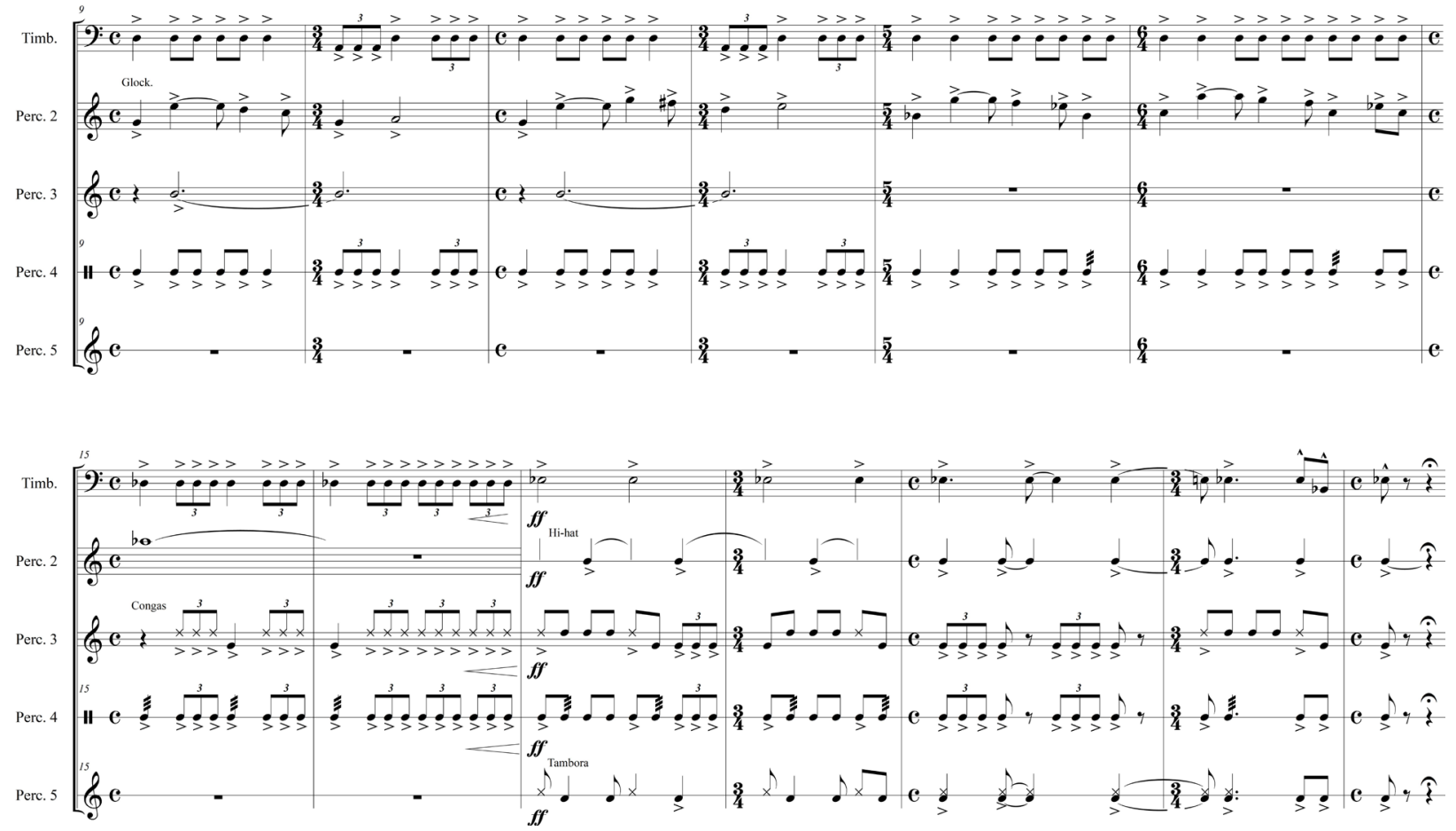

Fuente: Ministerio de Cultura República de Colombia, 2010, pp. 2-4. 
Imagen 2. I movimiento: Nueva Granada, compases 22 y 23

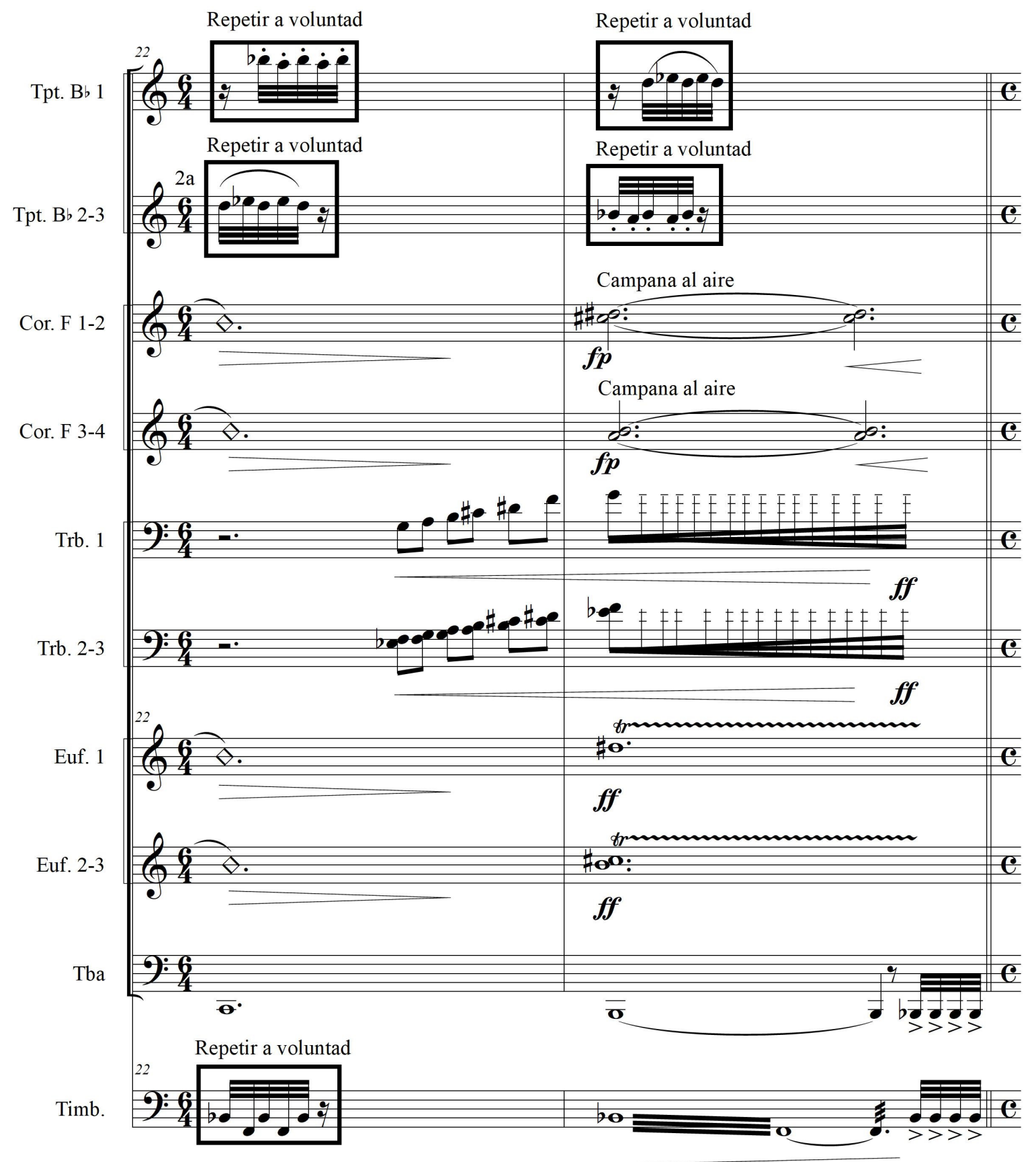

Fuente: Ministerio de Cultura República de Colombia, 2010, p. 4. 
El nacionalismo musical: una mirada a partir de dos obras representativas

Artículo para banda sinfónica de compositores latinoamericanos

Imagen 3. I movimiento: primer tema (solo de trompeta), compases 25-29

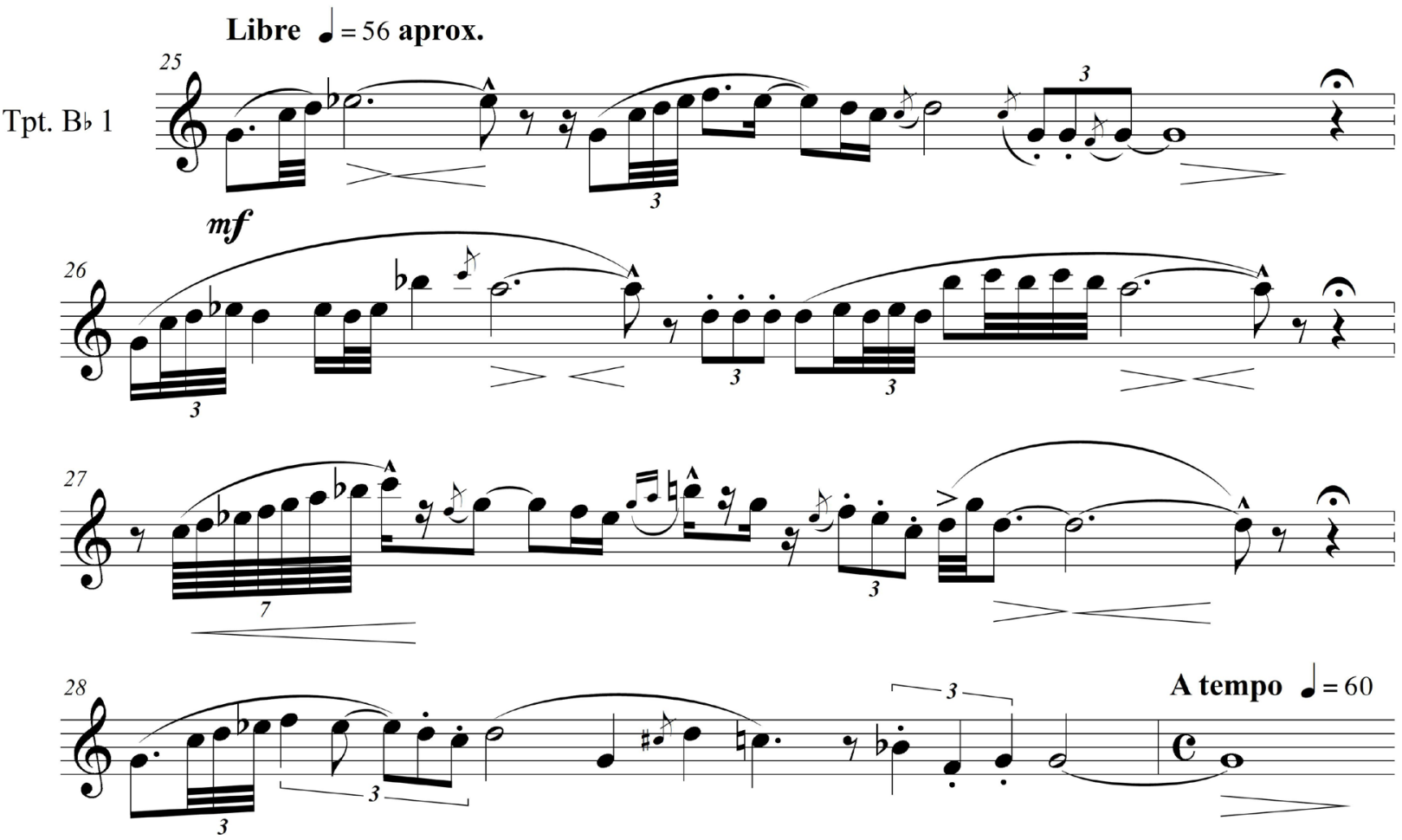

Fuente: Ministerio de Cultura República de Colombia, 2010, pp. 5-6.

y timpani (ver imagen 2). El primer tema del movimiento, expuesto en un maravilloso solo de trompeta de gran lirismo y expresividad, representa la imagen colonial, el "otro" (imagen 3).

Los siguientes compases de esta sección son un breve desarrollo del primer tema, presentado especialmente en las flautas, pícolo y oboes sobre patrones rítmicos repetidos en los demás instrumentos. Por su parte, "El florero y Cartagena" hace alusión a un incidente entre criollos y un español que, según fuentes consultadas, desencadenó una de las anécdotas más importantes de la historia de Colombia, la reyerta del 20 de julio de 1810. En esta sección, Valencia introduce el segundo tema, el cual representa el espíritu nacional. Es una melodía sencilla, pero muy lírica (imagen 4) expuesta en las flautas, corno inglés, fagotes y eufonios. Esta se presenta bajo un patrón rítmico basado en una acentuación característica de ritmos del Caribe colombiano $(3+3+2)$, donde, una vez más, el uso de la síncopa es privilegiado (imagen 5). 
Imagen 4. I movimiento: El florero y Cartagena, segundo tema, compases 41-44 El florero y Cartagena $\bullet=76$

Fl. 1-2

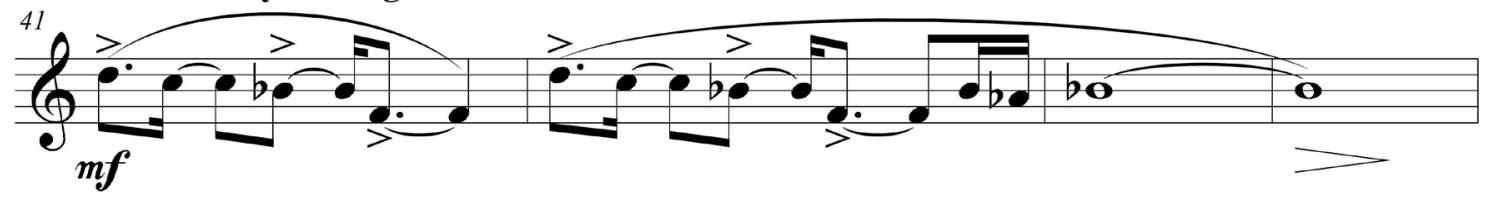

Fuente: Ministerio de Cultura República de Colombia, 2010, pp.10-11.

Imagen 5. I movimiento: El florero y Cartagena, segundo tema (acompañamiento), compases 41-44

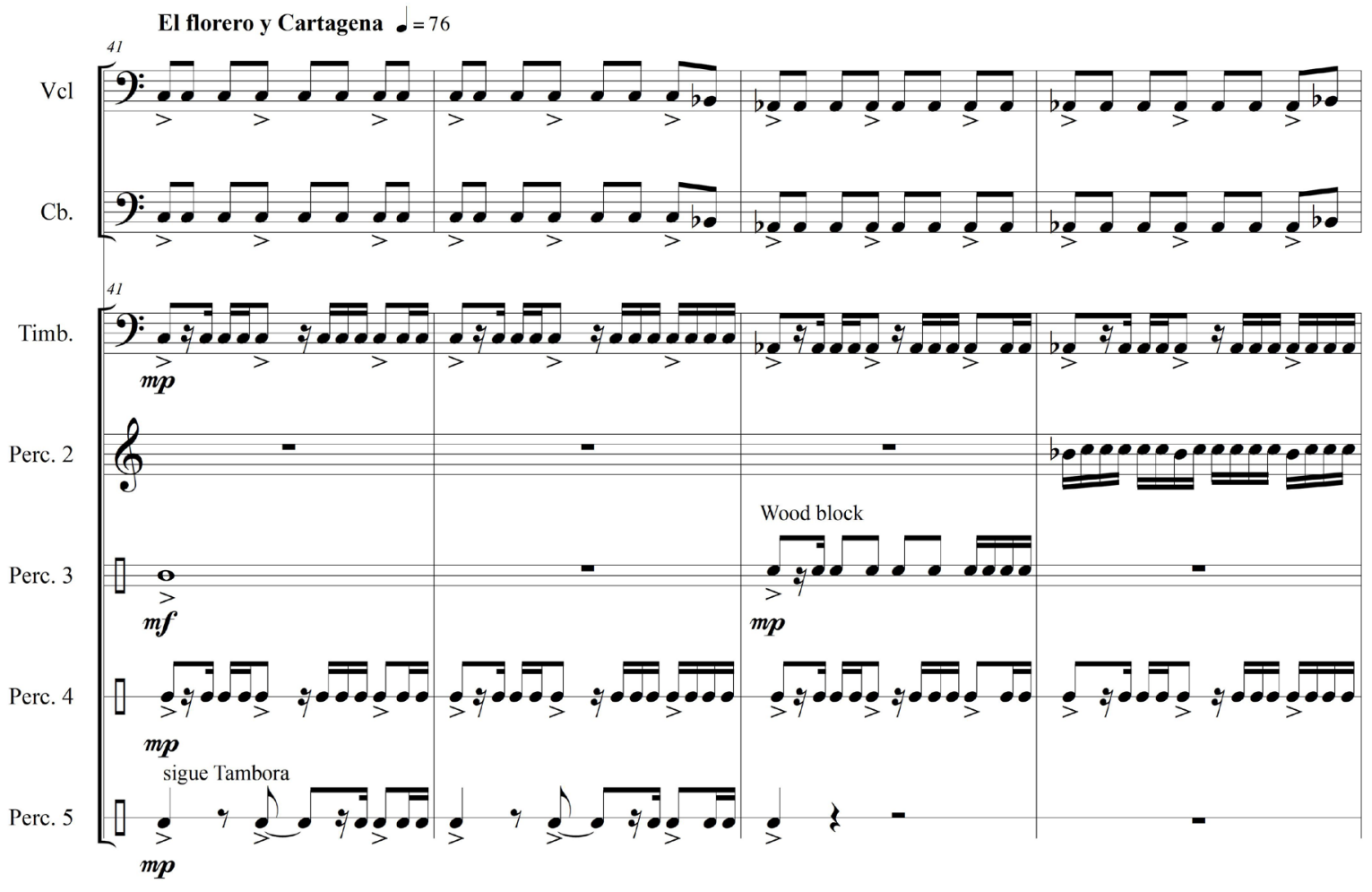

Fuente: Ministerio de Cultura República de Colombia, 2010, pp.10-11. 
El nacionalismo musical: una mirada a partir de dos obras representativas

Artículo para banda sinfónica de compositores latinoamericanos

En la sección "Patria Boba" se retoma el primer tema de "Nueva Granada". Primero, lo realiza con un intenso solo de fagot con un acompañamiento lírico en las flautas, sobre un ostinato rítmico en los clarinetes y el timbal, y una línea de bajos (violoncello, contrabajo) que sirve de base a toda esta estructura. Luego, el tema es tomado por los oboes, corno inglés y clarinetes, con un contrapunto en las flautas y saxofones alto y tenor, además de un bello coral de la sección de metales.

Luego de una pequeña transición, aparece la sección "Bolívar", en un tempo muy rápido y presentando diseños más ágiles y enérgicos, dispuestos en patrones de 3 y 5 pulsos. Pero siempre con una sensación de acentuación rítmica 3+3+2 en los bajos que crea una especie de síncopa, característica, como ya se ha dicho, de los ritmos del Caribe (imagen 6). Estos diseños se alternan con material de carácter más lírico tomado del segundo tema (imágenes 7 y 8)

Imagen 6. I movimiento: Bolívar, compases 107-113

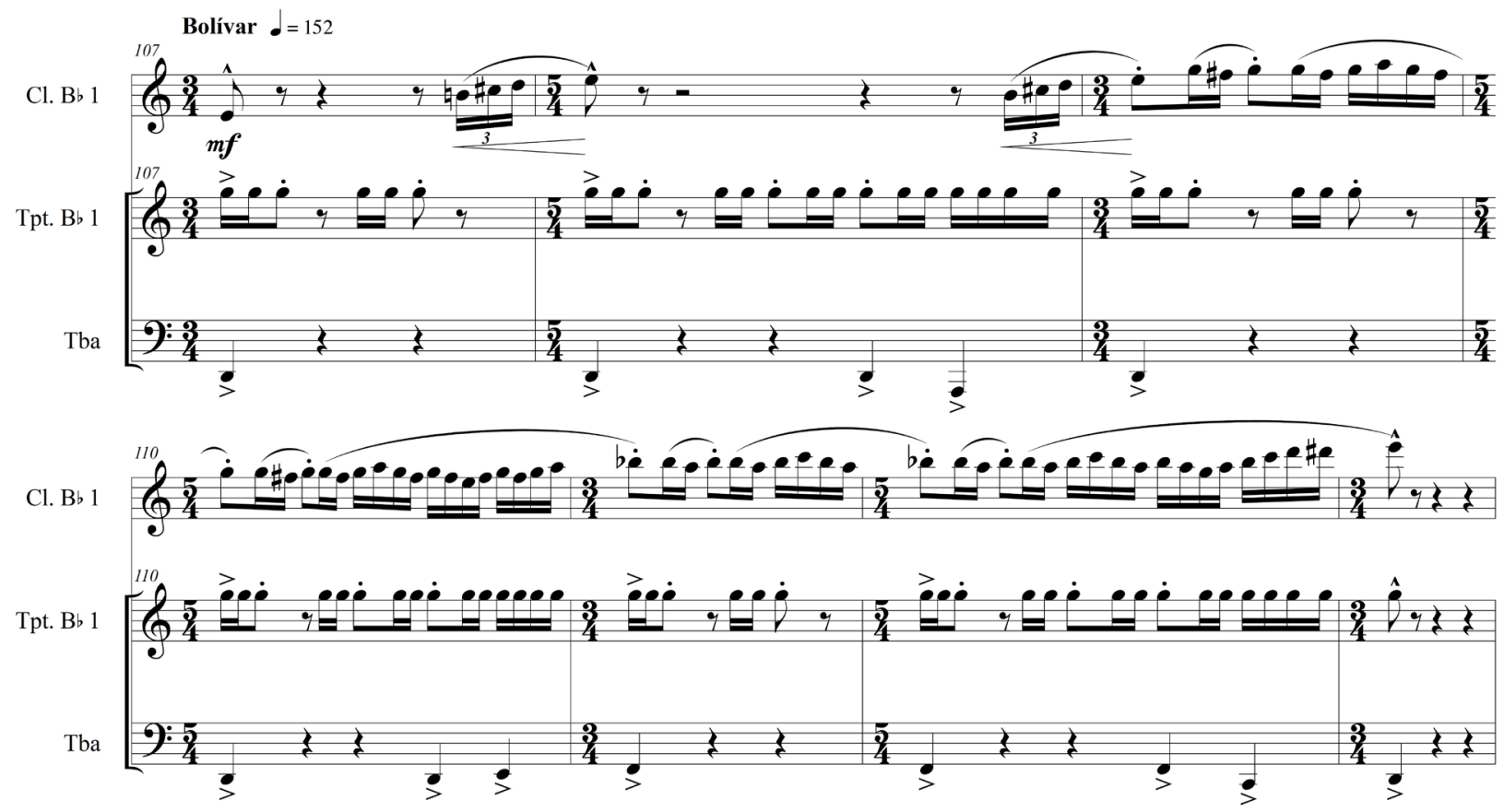

Fuente: Ministerio de Cultura República de Colombia, 2010, pp. 28-29. 
Imagen 7. I movimiento: compases 113-116

Sax. Alt. 1-2

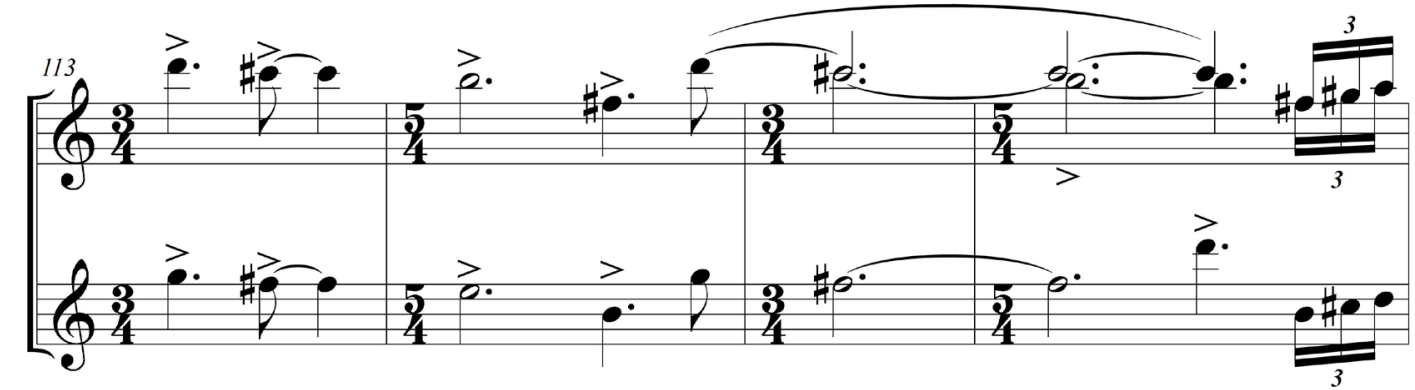

Fuente: Ministerio de Cultura República de Colombia, 2010, pp. 29-30.

Imagen 8. I movimiento: compases 149-156

Cor. F 1-2

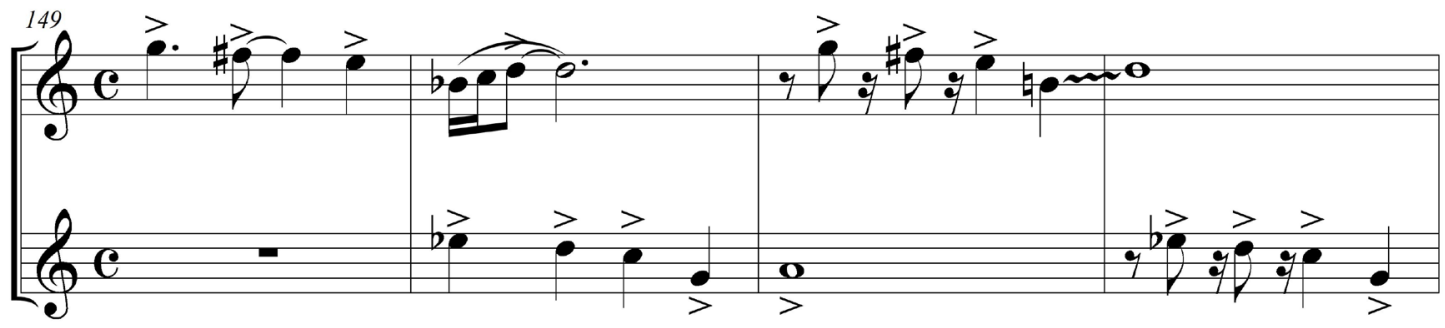

Tpt. B $b 1$
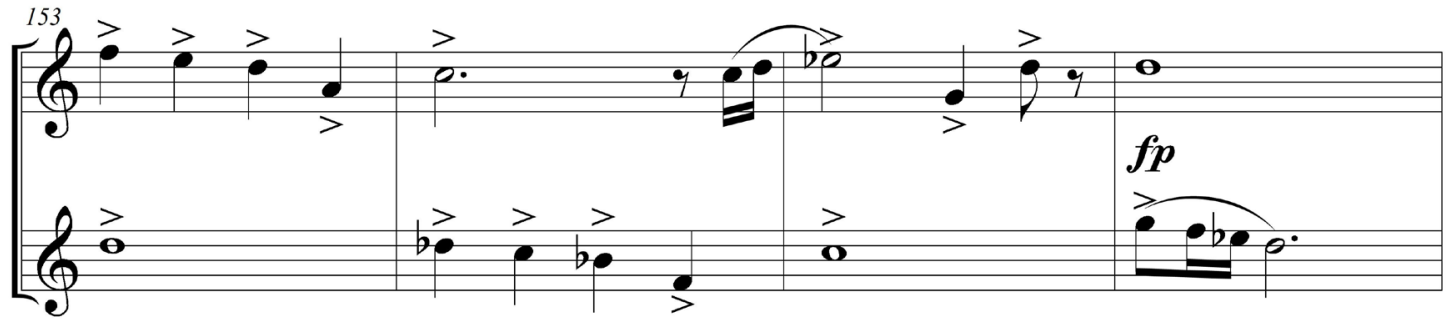

Fuente: Ministerio de Cultura República de Colombia, 2010, pp. 37-39.

Esta sección conduce hasta una cumbia de gaitas y tambores (imagen 10). "La música de gaita es una de las múltiples manifestaciones culturales que nacen del mestizaje triétnico resultante de la colonización española en América: una mezcla de las vertientes indígena, hispana y africana" (Convers \& Ochoa, 2007, citado por Pardo 2018, p. 6). De esta manera, Valencia utiliza en esta sección uno de los géneros que más identifica la costa caribeña colombiana, con los tambores de la cultura africana y las gaitas de la cultura indígena. La percusión usada es representativa del género de cumbia (tambor alegre, maracón, congas) fusionada con el redoblante moderno y el glockenspiel, xilófono y celesta. 
Incluso, escribe un solo de tambor alegre (imagen 9) para el cual, además, aporta la siguiente indicación: "toque y reproduzca onomatopeyas con la voz (grito)", una referencia a la cultura africana.

Imagen 9. I movimiento: solo de tambor alegre, compases 163-172

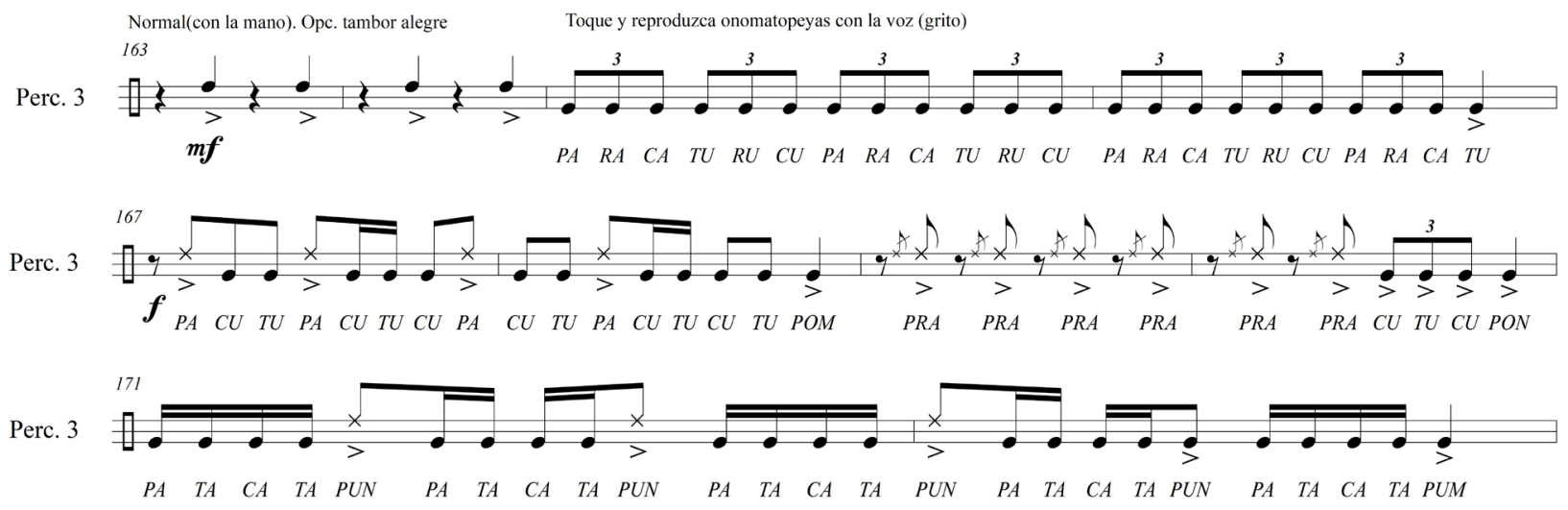

Fuente: Ministerio de Cultura República de Colombia, 2010, pp. 41-43.

La cumbia de gaitas y tambores es seguida de una breve transición que conduce a la última sección "República", que no es más que una re-exposición de "El Florero y Cartagena". Finalmente, presenta una coda con un nuevo solo de trompeta, la cual utiliza material del primer tema y que, en palabras del mismo Valencia, señala la condición de inter-dependencia en la construcción permanente de quiénes somos. En los siguientes dos movimientos, titulados "Territorios norte" y "Territorios sur",

se establecen contactos con referentes sonoros latinoamericanos, fortaleciendo los rasgos compartidos en la región a través de la historia colonial, así como los procesos culturales y sociales en tránsito. De esta manera, se encuentran el danzón y otros géneros de la música afrocubana en diálogo con el Caribe colombiano y el tango, en interacción con elementos de sistemas musicales andinos (Valencia, s.f., párr. 1).

Así mismo, Valencia hace referencia al movimiento llamado "Utopías" e indica que este último movimiento:

opera a manera de síntesis y prospección en tres segmentos principales: "Memoria", "Encuentro" y "Diversidad", más la Coda e "Interdependencia". Con ello, se recrean temas de los movimientos anteriores, especialmente de los dos primeros. 
Alternando contextos modales, tonales y de mayor libertad sistémica, al igual que texturas y técnicas de diversas tradiciones musicales, el vigor rítmico y la intención expresiva son los motores básicos de la suite, en coherencia con estos 200 años de búsqueda colectiva (Valencia, s.f., párr. 1).

Imagen 10. I movimiento: cumbia de gaitas y tambores, compases 173-180.

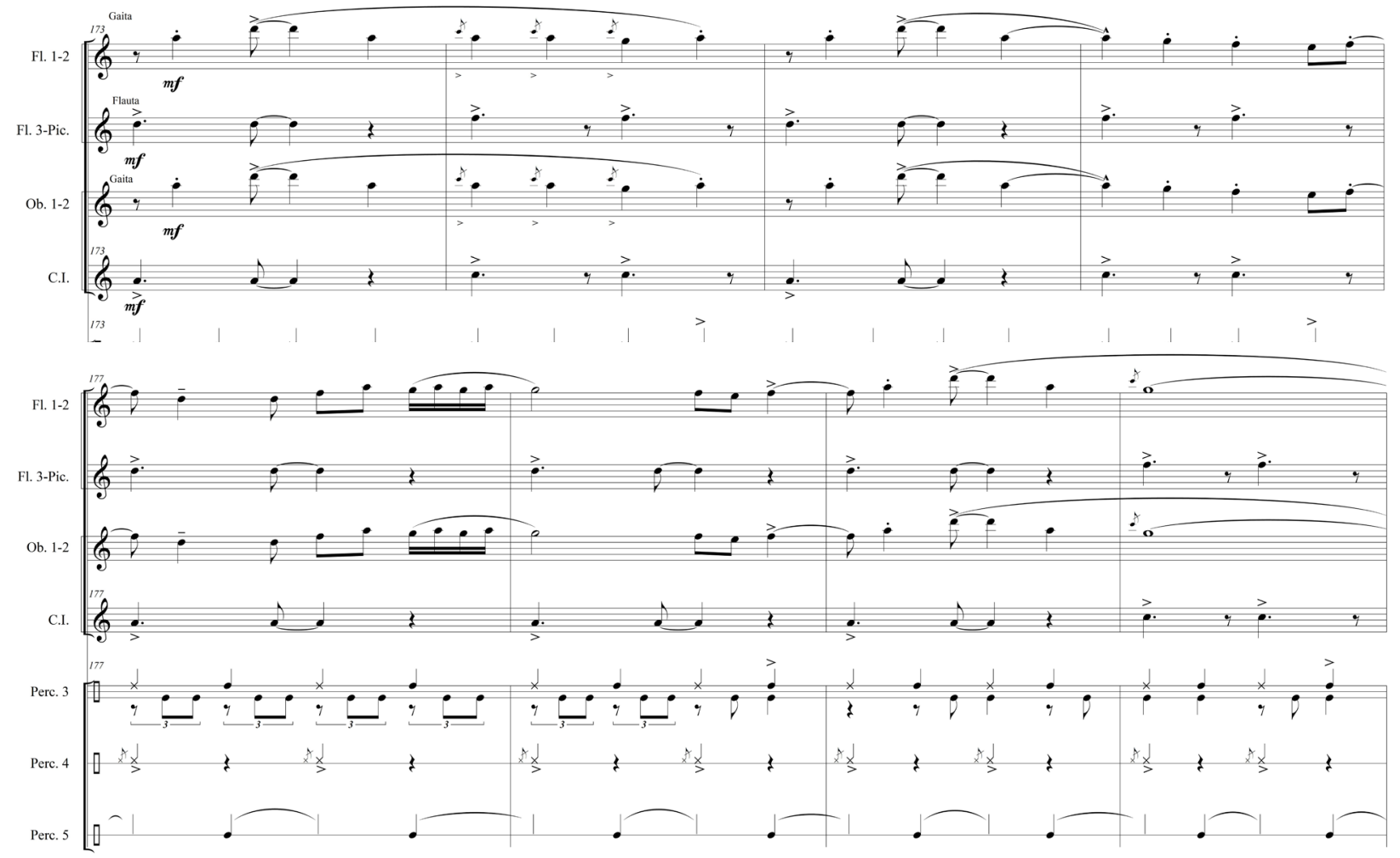

Fuente: Ministerio de Cultura República de Colombia, 2010, pp. 43-44.

Se puede decir que Valencia intenta expresar un estilo local o regional, con un lenguaje que adaptó parte de la tradición europea a la cultura urbana y campesina de su patria y de Latinoamérica. Es un artista que se proyecta cada vez más como una figura relevante de la música para banda sinfónica en Colombia. De esta forma, marca fuertemente el panorama musical latinoamericano de los siglos XX y XXI e influye, en buena medida, en otros compositores colombianos y latinoamericanos. 


\section{Preludio y Scherzo de Vinicio Meza}

Otro compositor latinoamericano que nació a finales del siglo XX con un trabajo muy interesante es Vinicio Meza, clarinetista, saxofonista, compositor y arreglista costarricense de música sinfónica, música de cámara, jazz y salsa. Inició sus estudios musicales con su padre, luego ingresó a la Escuela Municipal de Música de Paraíso, en la provincia de Cartago, Costa Rica, donde comenzó sus estudios de clarinete. Posteriormente, continuó en el Conservatorio de Castella, una escuela secundaria especializada en artes en Costa Rica. Al graduarse recibió una beca de la Academia de Artes de Interlochen, en Michigan, Estados Unidos, donde estudió durante dos años. Obtuvo el Bachillerato en Música del Instituto de Música Curtis, en Filadelfia, Estados Unidos y la Maestría en la Universidad Estatal de Florida, del mismo país (Chaves, s.f.).

Varias de sus obras han sido grabadas o comisionadas en Costa Rica y en el extranjero por agrupaciones como la Orquesta Sinfónica Nacional de Costa Rica, Cuarteto de Trombones de Costa Rica, Quinteto de Madera Miravalles, Octeto Académico de Caracas, en Venezuela, Indianapolis Bass Ensemble, Ensemble Capriccio de Minnesota en Estados Unidos y otros. Fue compositor, arreglista y director de la orquesta de música salsa Soncaribe. Con este grupo y con el cuarteto de jazz Swing en 4 realizó la música de la película del costarricense de Oscar Castillo Asesinato en el Meneo.

En Costa Rica, Meza ha recibido el Premio Nacional Aquileo J. Echeverría en composición musical, el premio al Arreglista del Año, el premio al Compositor del Año en la categoría de música formal y el premio al Compositor del Año en la categoría de jazz, otorgados por la Asociación de Compositores y Autores Musicales (ACAM), así como el premio Áncora en música. En el 2017, recibió el Premio Nacional de Música "Carlos Enrique Vargas". Fue el compositor invitado del XI Festival Internacional de Música. Ha sido profesor de clarinete en la Universidad de Costa Rica y en la Universidad Nacional. Actualmente, es clarinetista en la Orquesta Sinfónica Nacional de Costa Rica y profesor de apreciación musical en el Instituto Tecnológico de Costa Rica. Además, es clarinetista, saxofonista y compositor del cuarteto de jazz Swing en 4, grupo con el cual ha grabado cuatro discos y se ha presentado en diversos escenarios nacionales e internacionales en Alemania, Suecia, Argentina, Cuba y Canadá (Chaves, s.f.).

Meza cuenta con una gran reputación, tanto nacional como internacional. Adoptó un estilo personal particular y único, utiliza un lenguaje no necesariamente innovador, pero 
sí muy característico y, en muchas ocasiones, con rasgos nacionalistas. Por un lado, es conocedor del lenguaje y de las tradiciones clásicas y románticas europeas, gracias a sus estudios formales en música. Por otro, es versado, de primera mano, en la música tradicional costarricense, el jazz, la música afrocaribeña y la llamada "música tropical", entendida esta última como la que ejecutan las orquestas o conjuntos en salones de baile muy populares en Costa Rica y otros lugares de Latinoamérica.

Por iniciativa propia, y de una manera mayormente autodidacta, desarrolló el gusto y el conocimiento por una gran cantidad de géneros y estilos de música popular de manera simultánea a sus estudios formales en la academia. Por esta razón, en su obra se pueden encontrar composiciones con formas, estructuras o desarrollos temáticos convencionales, como en la tradición clásica y romántica europea. Sin embargo, siempre se puede encontrar un ingrediente adicional que le imprime ese sello personal y que deviene de todo ese aprendizaje en "la calle", que se convirtió en complemento al aprendizaje del ambiente académico y de la tradicional educación musical occidental. Así, pues, Meza ha tenido numerosas influencias, pero se ha inspirado principalmente en el jazz, así como en la música popular y folclórica de Costa Rica y el Caribe. Ha mantenido de manera muy clara su propia identidad, por lo que ha utilizado para tal efecto un lenguaje musical académico. Debido a esto dio origen a un estilo que permite tanto un equilibrio formal como la expresión de sus sentimientos.

Lo anterior no quiere decir que haya sido ajeno a las nuevas posibilidades de la composición de la música contemporánea occidental; perfectamente podría adscribirse a tendencias más modernistas, ya que utiliza, por ejemplo, métodos armónicos que excluyen, por decirlo de alguna manera, las reglas tradicionales. Meza emplea lo que considere necesario según la obra y es muy libre en este manejo. En algunas obras incluye material folclórico de manera directa o bien, lo estiliza en otras. Meza propone un material de su propia invención, pero trabajado con la utilización de elementos (melódicos y rítmicos) que dan la impresión de ser auténticamente folclóricos. Al escuchar algunas de sus obras, se percibe su excepcional absorción de estos elementos. Un ejemplo de ello es su Preludio y Scherzo, obra incluida en este análisis. Esta obra fue escrita originalmente para quinteto de contrabajos en 1995. El compositor luego realizó una adaptación para orquesta de cuerdas en el año 2001 y la versión para banda sinfónica en el 2009. Es una obra en dos partes: la primera, lenta y de carácter lírico; la segunda, rápida y con elementos musicales del tambito. 
Al escuchar el Scherzo, se percibe el ritmo de tambito, considerado original del folclor costarricense, aunque realmente su origen ha suscitado acaloradas polémicas. Según Hidalgo (2018), "al realizar una revisión bibliográfica, teniendo como propósito la localización de trabajos que aborden la cuestión folclórica costarricense, se puede notar que dicha temática no ha motivado en gran cuantía el interés de los investigadores sociales de Costa Rica" (p. 90). Sin embargo, algunos autores, como Jaime Rico Salazar, refiere este ritmo como típico de la provincia de Guanacaste. "According to Salazar, in Costa Rica the "tambito" qualifies as "el ritmo más típico costarricense". Its rhythm is syncopated 3/4 time and originate in the province of Guanacaste. The term "tambito is the diminutive form of 'tambo' i.e. 'rancho que se construye en las haciendas para que los peones vayan a pernoctar y cuidar las siembras' [Según Salazar, en Costa Rica el "tambito" califica como 'el ritmo más típico costarricense'. Su ritmo es sincopado en métrica de 3/4 y se origina en la provincia de Guanacaste. El término "tambito es la forma diminutiva de "tambo", es decir]" (Griffin, 1998, p. 440).

En todo caso, en el Scherzo de Meza es evidente el uso de este particular ritmo. Escrito en un compás de 6/8 y en un tempo rápido, el compositor hace uso de una melodía original que remite a lo que comúnmente se conoce como música folclórica costarricense. Esto lo realiza a partir de la base del tambito y con un tratamiento del ritmo que provee a la obra de un constante dinamismo, como se puede apreciar en su tema principal (imagen 11). Este procedimiento se puede entender como la práctica de inventar temas "populares" o "motivos auténticos" para darles cierto realce cultural, por medio de una estilización, en un contexto de tonalidades y/o métricas modernistas disfrazadas, por así decirlo. Una cita que, aunque se refiere a compositores del siglo XX, resume esta técnica es la siguiente:

El repertorio de la época está lleno de obras de corte modernista en donde se incorporan melodías o secuencias de intervalos basados en material folclórico o popular. En muchas ocasiones este hecho no es obvio, ¿cuántos de nosotros reconoceríamos la presencia de material folclórico en la Consagración de la Primavera? (Vilar-Payá, 2005, p. 216).

La obra de Meza es un excelente ejemplo de nacionalismo en el que los referentes culturales nativos se manifiestan de manera indiscutible; pero, en ciertas ocasiones, son disfrazados en su esencia musical y colocados dentro de un aventurado marco modernista. De esta manera, al igual que sucedió con algunos compositores latinoamericanos del siglo $X X$, es un artista que no puede ser juzgado única o exclusivamente como nacionalista, por- 
que lo nacional está incorporado en su música de distintas y personalizadas maneras, por ejemplo, utiliza elementos viejos y nuevos, uniendo lo culto con lo popular. El poeta Rafael Alberti, después de escuchar algunas obras del compositor mexicano Silvestre Revueltas (1899-1940), publicó: "muy mexicana su música, nada localista; popular, pero sin transcripciones" (Revueltas, 1989, p. 146).

Imagen 11. Preludio y Scherzo, Vinicio Meza. Scherzo: tema principal, compases 11-21
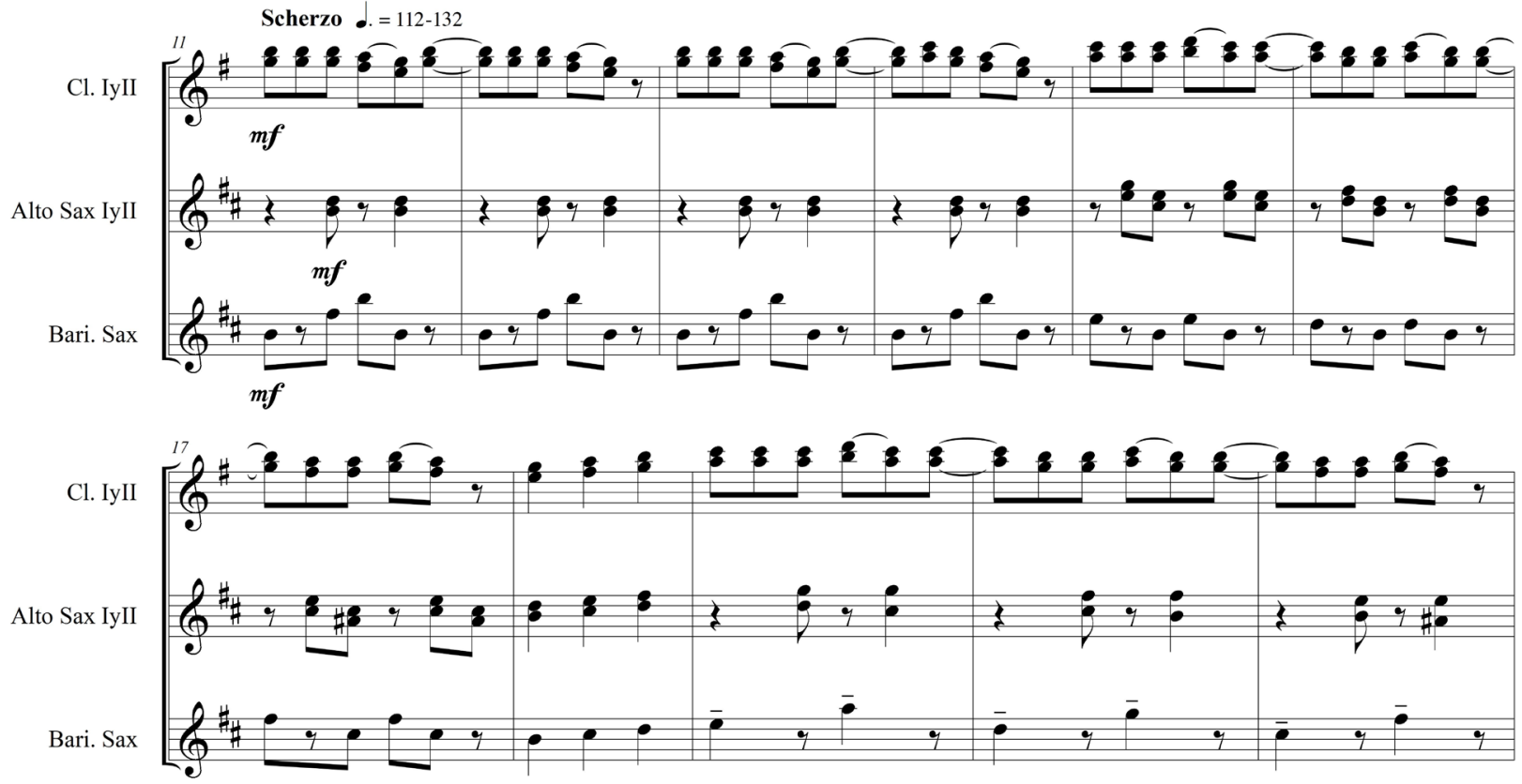

Fuente: Meza, 2009, pp. 7-9.

Otro procedimiento que se puede encontrar en la música de Vinicio Meza, muy usado también por algunos compositores latinoamericanos de la primera mitad del siglo XX, es la utilización de derivados abstractos de temas populares; es decir, motivos musicales modificados, extraídos de canciones o piezas populares. De manera que, en algunas ocasiones, es difícil detectarlos. Estas modificaciones se pueden hallar ya sea en un patrón rítmico particular, un color instrumental característico, una sección, una forma particular de articulación o fraseo, un diseño melódico o la combinación de alguno de estos recursos. Puede ser un motivo empleado como núcleo generador de desarrollo musical que aparece y reaparece sistemáticamente o, todo lo contrario, siempre de forma aislada. Sin embargo, cada vez que reincide, por lo general, es modificado. 
Esta abundancia de ideas, la transformación continua y el rechazo de las limitaciones que sugiere la tradición son parte de la propuesta del costarricense. El ritmo es de vital importancia en la música de Meza. Se convierte en un elemento que provee dinamismo, continuidad, estabilidad y dirección a su música; es decir, la presencia tenaz del ritmo como elemento fundamental para sustentar la continuidad del texto musical. Además, en su discurso emplea técnicas de desarrollo basadas en la elaboración melódica. Tiene el don de la melodía. Un ejemplo claro de esta afirmación es el preludio de su obra Preludio y Scherzo, basada en una sencilla línea melódica, pero que está provista de gran lirismo y expresividad, (imagen 12) sobre una rica armonía que sirve de complemento para lograr un resultado que cautiva no solamente al público, sino a los mismos ejecutantes.

Imagen 12. Preludio: compases 1-9

Cl. IyII

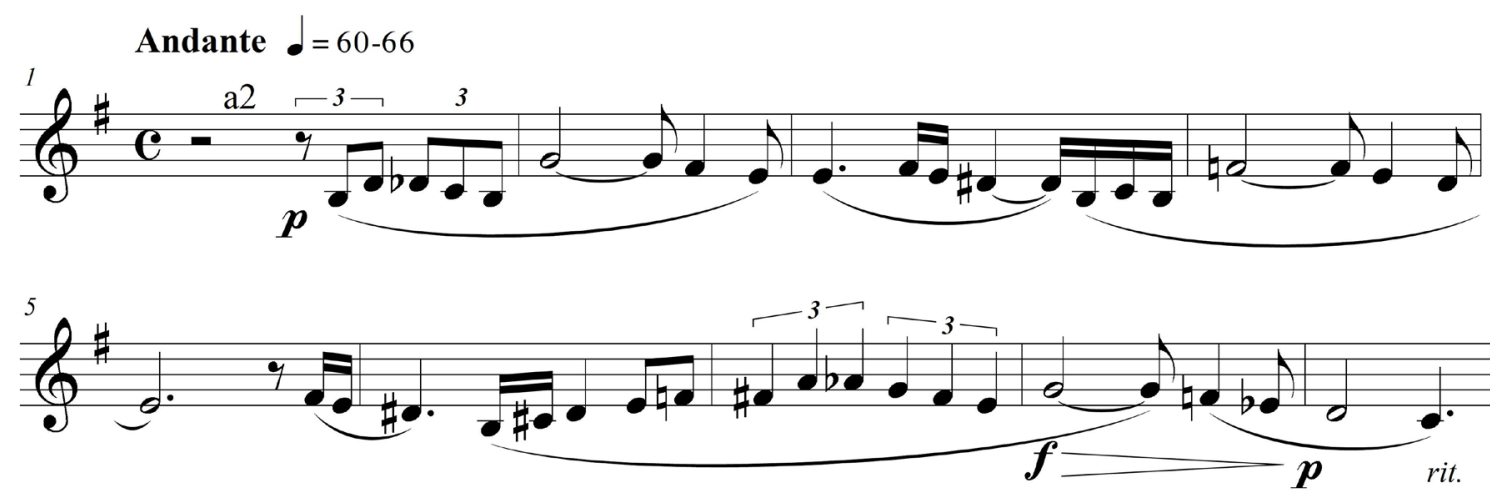

Fuente: Meza, 2009, pp. 1-2.

En general, el uso del contrapunto es muy particular en su obra. El compositor logra de manera excepcional coincidir en forma controlada distintas líneas melódicas que poseen una identidad específica. La mayoría de sus composiciones son breves. Siguiendo la asociación con los compositores de primera mitad del siglo XX, esta brevedad en las partituras era entendida en algunos revolucionarios, no solamente latinoamericanos, sino también europeos, como una denuncia de los excesos del romanticismo. Preludio y Scherzo tiene una duración aproximada de ocho minutos.

En relación con este tipo de composición breve, Kolb dice: "dentro del canon de la música occidental, estos conceptos no representan propiamente géneros musicales: se entienden mejor como 'no-géneros', es decir, como el resultado de una negación de lo que entonces era convencional" (2005, p. 188). Sin embargo, no es el caso de Meza, ya 
que también puede entenderse como el deseo de comunicar al oyente una idea musical de manera concisa, sin rodeos.

Se puede decir que el estilo de Meza se respalda básicamente en dos referentes: uno externo, que es el lenguaje clásico-académico occidental y uno interno o local, que es la música de su entorno propio. En ambos casos utiliza procedimientos o técnicas muy originales para tratar los recursos o elementos. Es poseedor de una gran audacia y creatividad al combinar los materiales de esos dos referentes citados en epígrafes. Esto nos lleva a considerar que, dentro de las propuestas nacionalistas, se da una especial elección por parte del compositor de ciertos elementos característicos del propio movimiento en su más amplio sentido político, social, cultural. De esta forma, como es de esperar, la estética musical se ve enriquecida de diversas maneras según sean las características locales que predominen en el ambiente en el que se desarrollan.

\section{Conclusiones}

Tanto en Europa como en Latinoamérica ha existido la tendencia nacionalista en la música para banda sinfónica del siglo XX. Específicamente en América Latina, se cuenta con figuras representativas, cuyas técnicas y procedimientos de composición pueden estar relacionados con los de algunos compositores pioneros de este movimiento en el siglo XIX en la región. Así, se pueden encontrar obras con una nueva conciencia estética que valoran la tradición, el folclor y las canciones populares, y hacen uso de ellas en el contexto de la música académica. Aunque es usual escuchar que los estilos nacionalistas condujeron hacia una ruta fácil de la expresión regionalista y a un alejamiento de las nuevas tendencias internacionales, en su momento compositores como Villa-Lobos, Revueltas y Roldán, y, en la actualidad, nuevas generaciones como Valencia y Meza, aprovechan las tendencias nacionalistas y los recursos que estas proveen, al adaptarlas a la tradición latinoamericana. Sus obras, en general, respondieron y responden a los requerimientos técnicos y a las necesidades musicales de la época. De esta manera, la música latinoamericana entra en la palestra universal con artistas que presentan propuestas y expresiones novedosas que llaman la atención de los oyentes y que tienen el exotismo como uno de sus principales atractivos. Sin duda, un arte musical nuestro y digno de respeto en cualquier parte del mundo.

Como se ha explicado en este trabajo, estas obras son un ejemplo del importante aporte del nacionalismo en la música para banda sinfónica del siglo XX. Es fundamental que tanto instrumentistas como directores, a través de la investigación no solamente del 
contexto histórico de la obra, sino también de los elementos de forma y composición, estudien, aprendan y pongan en práctica todos los detalles distintivos de la música de cada región, para lograr una mejor interpretación.

Finalmente, este trabajo pretende ser un insumo importante para los músicos de bandas costarricenses y, a la vez, una invitación a reflexionar sobre la importancia de hacer trascender la música para banda sinfónica latinoamericana y nacional, ya que existe y de muy buena calidad, creada por compositores con un alto grado de compromiso por prestigiar la música de la región al colocarla en un alto nivel mundial.

\section{Referencias}

Béhage, G. (1983). La música en América Latina. Caracas, Venezuela. Monte Ávila Editores, C.A.

Béhague, G. (2006). La problemática de la posición socio-política del compositor en la música nueva en Latinoamérica. Latin American Music Review / Revista de Música Latinoamericana, 27(1), 47-56.

Caines, J. E. (2012). Frederick Fennell and the Eastman Wind Ensemble: The Transformation of American Wind Music through Instrumentation and Repertoire (tesis para obtener el grado de master). Universidad de Ottawa, Canadá. Recuperado de https://search-proquest-com.ezproxy.sibdi.ucr.ac.cr/docview/1355961698?accountid=28692

Carpentier, A. (2004). América Latina en la confluencia de coordenadas históricas y su repercusión en la música. En I. Aretz (ed.), América Latina en su música. Recuperado de https://books.google.com.pe/books?id=3xclSef_HKOC\&printsec=frontcover\&hl=es\&source=gbs_ge_summary_r\&cad=0\#v=onepage\&q\&f=false

Chase, G. (1947). Fundamentos de la cultura musical en Latino-América. Revista Musical Chilena, 3(25-26), 14-23.

Chatski, E. (2012). El nacionalismo musical en Costa Rica. Revista Káñina, 36, 27-29. Recuperado de http://www.redalyc.org/articulo.oa?id=44249255029

Chaves, M. (s.f.). Vinicio Meza [sitio web]. Recuperado de https://si.cultura.cr/personas/ vinicio-meza.html 
Cordero, R. (2004). Vigencia del músico culto. América Latina en su música. México: Siglo XI Editores.

Cruz, M. A. (2002). Folclore, música y nación: El papel del bambuco en la construcción de lo colombiano. Nómadas, 219-231.

Falabella, R. (1953). Problemas estilísticos del joven compositor de Chile. Revista Musical de Chile, 41-49. Recuperado de http://revistas.uchile.cl/index.php/RMCH/article/viewFile/12506/12816

Griffin, R. (1988). The Folk Music of Costa Rica: A Teaching Perspective. Hispania, $71(2)$, 438-441. doi:10.2307/343094

Hidalgo, A. (2018). Las nociones de lo 'costarricense' en la música folclórica de los años 80. El caso del grupo cantares. Káñina, 42(1), 89-117.

Kolb, R. (2005). Silvestre Revueltas y el Panfleto. En: Discanto, ensayos de investigación musical. México: Editorial Universidad Veracruzana.

Kuss, M. (1998). Nacionalismo, identificación, y Latinoamérica. Cuadernos de Música Iberoamericana, 6,133-49.

Meza, J. C. (2008). Aporte cultural de la Banda Nacional de Cartago al pueblo cartaginés. La Retreta. 1(2). Recuperado de http://laretreta.net/0102/articulos/bandacartago.html

Meza, V. (2009). Preludio y Scherzo for concert band. Costa Rica: Filarmonika Music Publishing.

Ministerio de Cultura República de Colombia. Banco Mundial de Partituras. Plan Nacional de Música para la Convivencia. (2010). 200, Tercera Suite para Banda. Bogotá D.C.: Fundación Nacional Batuta.

Miranda, R. \& Tello, A. (2011). La música en Latinoamérica. Secretaría de Relaciones Exteriores México. Dirección General de Acervo Histórico Diplomático.

Müller-Bergh, K. (1969). Corrientes vanguardistas y surrealismo en la obra de Alejo Carpentier. Revista Hispánica Moderna, 35(4), 223-340. Recuperado de https://www-jstor-org.ezproxy.sibdi.ucr.ac.cr/stable/pdf/30203080.pdf?refreqid=excelsior\%3A0822fc247416bf1f9c1d533473e8738a 
El nacionalismo musical: una mirada a partir de dos obras representativas

Artículo

para banda sinfónica de compositores latinoamericanos

Pardo, R. (2018). Aproximaciones compositivas desde ritmos de gaita y bullerengue (trabajo de investigación). Pontificia Universidad Javeriana. Recuperado de https://repository.javeriana.edu.co/bitstream/handle/10554/35254/Aproximaciones\%20compositivas\%20 desde\%20ritmos\%20de\%20gaita\%20y\%20bullerengue.pdf?sequence=1\&isAllowed=y

Parra, C. (2010). Tendencias musicales en el nacionalismo venezolano desde la música coral de Modesta Bor. Revista de Investigación, 34(69), 77-105. Recuperado de http://revistamusicaldevenezuela.com.ve/wp-content/uploads/2017/09/RMV-51-Dosier-RMVN\%C2\%B051.pdf

Picún, O. \& Carredano, C. (2012). El nacionalismo musical mexicano: una lectura desde los sonidos y los silencios. En El arte en tiempos de cambio 1810-1910-2010. Recuperado de https://www.latinoamerica-musica.net/historia/sitio-picun-carredano\%2022--XI-12.pdf

Plesch, M. (2008). La lógica sonora de la generación del 80: Una aproximación a la retórica del nacionalismo musical argentino. Los caminos de la música (Europa-Argentina). Argentina: Editorial de la Universidad Nacional de Jujuy.

Revueltas, S. (1989). Silvestre Revueltas, por él mismo: apuntes autobiográficos, diarios, correspondencia y otros escritos de un gran músico (comp. Rosaura Revueltas). México: Ediciones Era. Recuperado de https://books.google.co.cr/books?id=KjstIIAIJOEC\&printsec=frontcover\&dq=inauthor:\%22Rosaura+Revueltas\%22\&hl=es\&sa=X\&ved=2ahUKEwjZvM_43ZHtAhUu1VkKHT6pC1kQ6AEwAHoECAAQAg\#v=onepage\&q\&f=false

Robertson, A. \& Stevens, D. (1985). Historia General de la Música. Madrid: Editorial Alpuerto, S.A.

Sánchez, I. (2011). VII Ciclo de ensayos generales con escolares. Fundación Cajasol Real Orquesta Sinfónica de Sevilla [Guía pedagógica]. Recuperado de https://docplayer. es/63295702-Vii-ciclo-de-ensayos-generales-con-escolares-fundacion-cajasol-real-orquesta-sinfonica-de-sevilla.html

Tello, A. (2004). Aires nacionales de América Latina como respuesta a la búsqueda de identidad. Hueso Humero, 44, 212-239. Recuperado de http://www.comunidadandina.org/ BDA/hh44/20AIRES\%20NACIONALES\%20EN\%20LA\%20M\%C3\%9ASICA.pdf

ESCENA. Revista de las artes, 2021, Vol. 81, Núm. 1 (julio-diciembre), pp. 134-169 
Tinoco, E. (2009). El nacionalismo en la obra para piano solo del compositor brasileño Camargo Guarnieri (tesis para optar por posgrado). Universidad de Chile. Recuperado de http://repositorio.uchile.cl/tesis/uchile/2009/ar-tinoco_e/pdfAmont/ar-tinoco_e.pdf

Valencia, V. (2011). Bandas de Música en Colombia. La creación musical en la perspectiva educativa. A Contratiempo: revista de música en la cultura, (16), 1-9. Recuperado de https://dialnet.unirioja.es/servlet/articulo?codigo=7619521

Valencia, V. (2017). Música Para Banda en Colombia. Territorios, Sentidos de la creación y rasgos del arreglista-compositor. (Pensamiento), (Palabra)... Y Obra, 18(18), 101111. Recuperado de https://dialnet.unirioja.es/servlet/articulo?codigo=6244351\&orden=0\&info=link

Valencia, V. (s.f.a). Biografía [sitio web]. Recuperado de victorianovalencia.com/index.php/ biografia

Valencia, V. (s.f.b). 200. Tercera Suite [sitio web]. Recuperado de http://www.victorianovalencia.com/index.php/tienda/banda/item/51-200-tercera-suite

Vilar-Payá, L. (2005). La originalidad, la música heterogénea y la recepción de Silvestre Revueltas a partir de Otto Mayer-Serra. En Discanto, Xalapa, Universidad Veracruzana. 205-218. Recuperado de www.enmusica.unam.mx 